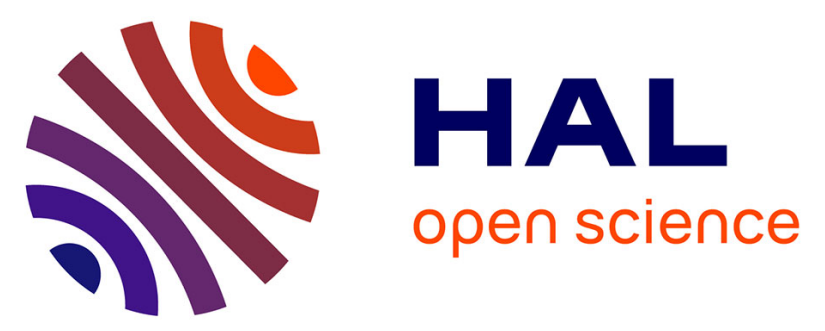

\title{
Delay in micro-discharges appearance during PEO of Al: Evidence of a mechanism of charge accumulation at the electrolyte/oxide interface
}

J. Martin, A. Nomine, F. Brochard, J. L. Briançon, C. Noël, T. Belmonte, T. Czerwiec, G. Henrion

\section{To cite this version:}

J. Martin, A. Nomine, F. Brochard, J. L. Briançon, C. Noël, et al.. Delay in micro-discharges appearance during $\mathrm{PEO}$ of $\mathrm{Al}$ : Evidence of a mechanism of charge accumulation at the electrolyte/oxide interface. Applied Surface Science, 2017, 410, pp.29-41. 10.1016/j.apsusc.2017.03.088 hal-02106037

\section{HAL Id: hal-02106037 \\ https://hal.univ-lorraine.fr/hal-02106037}

Submitted on 10 May 2019

HAL is a multi-disciplinary open access archive for the deposit and dissemination of scientific research documents, whether they are published or not. The documents may come from teaching and research institutions in France or abroad, or from public or private research centers.
L'archive ouverte pluridisciplinaire HAL, est destinée au dépôt et à la diffusion de documents scientifiques de niveau recherche, publiés ou non, émanant des établissements d'enseignement et de recherche français ou étrangers, des laboratoires publics ou privés. 
Delay in micro-discharges appearance during PEO of Al:

Evidence of a mechanism of charge accumulation at the electrolyte/oxide interface

J. Martin ${ }^{1,2, *}$, A. Nominé ${ }^{1}$, F. Brochard ${ }^{1}$, J.-L. Briançon ${ }^{1}$, C. Noël ${ }^{1}$, T. Belmonte ${ }^{1}$, T.

Czerwiec $^{1,2}$, G. Henrion ${ }^{1,2}$

${ }^{1}$ Institut Jean Lamour, CNRS-Université de Lorraine, UMR CNRS 7198, Parc de Saurupt CS 50840, F-54011 Nancy cedex France

${ }^{2}$ Laboratoire d'Excellence Design of Alloy Metals for low-mAss Structures ('LabEx DAMAS'), Université de Lorraine, Ile du Saulcy, F-57045 Metz cedex France

*Corresponding author: Tel.: +33 383584251

julien.martin@univ-lorraine.fr, 


\section{Abstract}

PEO was conducted on Al by applying a pulsed bipolar current. The role of the cathodic polarization on the appearance of micro-discharges (MDs) and on the subsequent formation of the PEO oxide layers is investigated. Various ratios of the charge quantity $R C Q=Q_{p} / Q_{n}$ (defined as the anodic $Q_{p}$ to cathodic $Q_{n}$ charge quantity ratio over one current pulse period) in the range $[0.5 ; 6.0]$ were selected by changing the waveform parameters of the cathodic current while keeping the waveform of the anodic current unchanged. Results show that the appearance of MDs is delayed with respect to the rising edge of the anodic current; this delay strongly depends on both the processing time and the applied cathodic charge quantity. It is also evidenced that shorter delays promoted by high RCQ $(R C Q>1)$ values are associated with stronger MDs (large size and long life) that have detrimental effects on the formed PEO oxide layers. The thicker and the more compact oxide layer morphology is achieved with the intermediate RCQ $(R C Q=0.9)$ for which the delay of the MDs appearance is high and the MDs softer. Low RCQ $(R C Q<0.9)$ results in an earlier extinction of the MDs as the process goes on, which leads to poorly oxidized metal. A mechanism of charge accumulation taking place at the oxide / electrolyte interface and arising before the occurrence of dielectric breakdown is proposed to explain the ignition of MDs during pulsed bipolar PEO of aluminium. A close examination of the voltage-time response which can be adequately simulated with an equivalent RC circuit evidences the capacitive behaviour of the oxide layer and therefore confirms this proposed mechanism of charge accumulation.

Keywords: Plasma Electrolytic Oxidation (PEO); Pulsed bipolar current; Micro-discharges; Light emission detection; Transient analysis; Equivalent circuit 


\section{Introduction}

Plasma Electrolytic Oxidation (PEO) is a plasma-assisted electrochemical conversion process of metallic surfaces to produce protective ceramic coatings. [1-4]. PEO is particularly dedicated to light-weight metals (Al, Mg, Ti) and their alloys. When applied to aluminium alloys, the resulting PEO coating exhibits improved thermal-, wear- and corrosion-resistance because thick, hard, compact and adherent crystalline oxide layers can be achieved [5-10]. By applying high voltages to the electrodes, usually beyond the critical dielectric breakdown threshold of the growing oxide layer, the PEO process is characterized by the generation of numerous tiny and short-lived micro-discharges (MDs) that occur continuously over the processed surface [11-15]. As the PEO process can be conducted in diluted alkaline electrolytes and therefore complies with the recent environmental and health regulations, it gains considerable promises in various technological and industrial domains to replace conventional acid anodizing processes. Nevertheless, one of the main drawbacks of the PEO process, which restricts its use at the industrial level, lies in the relatively high costs of the treatment arising from high electric energy consumption associated with the application of high current densities (typ. $10-60 \mathrm{~A} / \mathrm{dm}^{2}$ ) and voltages (up to $300-400 \mathrm{~V}$ ). Research works devoted to improve the energy efficiency of the PEO process are abundant in the literature and the main ways that are proposed consist in adopting an engineering approach by adjusting the PEO processing parameters such as the electrolyte composition [16-21] and the applied electrical signal [22-29]. For example, by using a pulsed bipolar current to supply the electrodes, Jaspard-Mécuson et al. established that the right setting of the current waveform parameters and the right control of both the anodic and cathodic charge quantity delivered to the electrodes over one current pulse period is crucial to promote the rapid formation of compact and thick oxide layers [23], thus reducing the energy consumption. 
On the other hand, the large-scale application of the PEO process is also limited because there is still no clear understanding of the physical mechanisms that are responsible for the oxide growth during PEO, even if progresses have been made over the past few years in proposing phenomenological description. In this context, few authors have provided mechanisms of PEO coating formation. It is also generally accepted that such mechanisms can be divided into two categories, those that tend to explain the oxidation of the metal under the presence of the MDs [30-35] and those that tend to describe the dielectric breakdown of the growing oxide immersed in a conductive electrolyte, which results in the MDs ignition [36-41]. In the first category, by considering the metal / oxide / electrolyte system, Klapkiv proposed a one-discharge model directly inspired from the model of steam and gas vial [3031]. Later, on the basis of experimental data, Sundararajan et al. have proved that the growth of oxide layers results from the molten material that is subsequently oxidized during ejection from the discharge channel, rapidly solidified by the surrounding electrolyte and re-deposited on the processed surface [32-33]. Yerokhin et al. consider two concomitant mechanisms of oxidation including electrochemical surface oxidation and plasma chemical oxide synthesis in discharge channels [34]. Matykina et al. used the ${ }^{18} \mathrm{O}$ isotope as a tracer to explain the oxidation mechanism within PEO conditions [35]. They showed that transport of oxygen is performed owing to two mechanisms including diffusion of oxygen in the solid state and decomposition of water molecules trapped in small defects (porosities and cracks) to form ions and radicals under the plasma. Concerning the second category of mechanisms, i.e. those describing the ignition of MDs during PEO, Hussein et al. [36-37] proposed a multi-discharge model involving three types of MDs occurring at different places and times through the oxide thickness: A-type MDs occur in relatively small holes or impurities near the topmost surface of the oxide layer, B-type MDs develop throughout the overall thickness of the oxide layer and C-type MDs ignite in the micro-pores of oxide layer. On the basis of optical emission 
spectroscopy results performed during PEO of aluminium, Jovovic et al._confirmed the presence of these three types of MDs [38]. In the case of PEO in silicate electrolyte, Dehnavi et al. show that A-type MDs occurring at the topmost surface of the oxide layer are due to silicon anions adsorbed on the metal surface [39]. More recently, Cheng et al. modified Hussein's model by adding two other types of MDs (D- and E-type) in order to take into account the presence of an outer porous layer and an inner compact layer separated by large porosity regions filled with electrolyte [40-42]. Concerning the appearance of MDs recorded under AC PEO conditions, Arrabal et al. were the first to report a delay between their detection and the anodic current pulse, MDs occurring later with respect to the rising edge of the current [43]. Though the authors observed slight differences in the delay as a function of the nature of the magnesium alloys that were studied, no thorough investigation into the origin of such phenomena has been conducted since then. By using a pulsed bipolar current, Mehlem also observed that MDs events are delayed with respect to the rising edge of the anodic current [44]. Nevertheless, clear explanations about the origin of such phenomena are still pending and more systematic investigations are needed.

Based on the use of pulsed bipolar PEO conditions on aluminium, the present study focuses on the influence of the charge quantity ratio on the delay of the MDs appearance in order to better understand the mechanisms that are responsible for the dielectric breakdown of the growing oxide and therefore for MDs ignition. To this purpose, the collected results from the in situ PEO process characterization (voltage- and current-time responses, light emission and MDs) and from the ex situ PEO coatings characterization (morphology, elemental and crystallographic composition) are firstly introduced. Secondly, based on the discussion of the collected results, a mechanism of charge accumulation occurring at the electrolyte/oxide layer interface is proposed. 


\section{Experimental}

\subsection{Material and PEO treatments}

A commercial 2214 grade aluminium alloy was used as substrate (content in weight $\%, 3.9-5 \mathrm{Cu}, 0.5-1.2 \mathrm{Mg}, 0.4-1.2 \mathrm{Mn}, 0.5-1.2 \mathrm{Si}, 0.5 \mathrm{Fe}, 0.5 \mathrm{Ti}, 0.25 \mathrm{Zn}, \mathrm{Al}$ as balance). Prior to process, all the samples $\left(50 \times 30 \times 6 \mathrm{~mm}^{3}\right.$ in size $)$ were ground with 1200 SiC paper, ultrasonically degreased in acetone, dried in warm air, and then immersed in the electrolyte. The PEO process was run in a solution of potassium hydroxide $\left([\mathrm{KOH}]=1 \mathrm{~g} . \mathrm{L}^{-1} \cong\right.$ $\left.0.018 \mathrm{~mol} . \mathrm{L}^{-1}\right)$ and anhydrous sodium silicate $\left(\left[\mathrm{Na}_{2} \mathrm{SiO}_{3}\right]=1.65 \mathrm{~g} . \mathrm{L}^{-1} \cong 0.014 \mathrm{~mol} . \mathrm{L}^{-1}\right)$ diluted in deionised water. The measured $\mathrm{pH}$ of the fresh electrolyte is 12.5 . Two titanium plates of $200 \times 200 \times 1 \mathrm{~mm}^{3}$ in size were used as counter-electrodes. They were symmetrically located at $90 \mathrm{~mm}$ apart from the aluminium sample. A cooling device allowed the electrolyte temperature to be kept in the range of [25-30 ${ }^{\circ} \mathrm{C}$ ]. As suggested in Ref. [45], after each treatment, the aged electrolyte was removed from the electrolysis tank and replaced with a fresh one in order to limit the ageing effect of the electrolyte. The PEO treatments were conducted by using a pulsed bipolar current from an electrical generator working in galvanostatic mode (Ceratronic ${ }^{\circledR}$ process [46]). The processed samples were supplied with an asymmetrical quasi-square current waveform. As depicted in Ref. [23], all the waveform parameters could be adjusted over a wide range of values. As reported in Table 1 and as illustrated in Fig. S1 in supplementary data, various ratios of charge quantity $(R C Q=0.5 ; 0.9$; $1.5 ; 1.6$ and 6$)$ were tuned and applied to the electrodes. They were designed by adjusting either the cathodic current amplitude $I_{\text {cath. }}$ (from -7 to $-21 \mathrm{~A}$ ) or the cathodic period duration $t_{\text {cath. }}$ (from 1.2 to $6 \mathrm{~ms}$ ) and by keeping the anodic current waveform unchanged. The anodic current amplitude was set at $I_{\text {anod. }}=20 \mathrm{~A}$, which corresponded to an anodic current density of $50.5 \mathrm{~A} . \mathrm{dm}^{-2}$. The anodic period duration was set at $t_{\text {anod. }}=3.4 \mathrm{~ms}$. The charge quantity ratio 
(RCQ) is defined as the ratio of the anodic $\left(Q_{p}\right)$ to cathodic $\left(Q_{n}\right)$ charge quantity [23]. Duration of the PEO process was set at 30 min for each sample.

\subsection{Material characterization}

The elaborated oxide layers were observed by scanning electron microscopy (FEGSEM Philips XL30). Top views of the processed surfaces and cross-sections views of the oxide layers were examined in SE (secondary electron) and BSE (back-scattered electron) mode, respectively. Prior to their characterization, samples were cut, mounted in resin, polished with successive grades of $\mathrm{SiC}$ abrasive papers and finely polished with a $1 \mu \mathrm{m}$ diamond paste. The phase composition of the layers was investigated by X-ray diffraction measurements $(\mathrm{XRD})$ using a Bruker D8 ADVANCE $\left(\mathrm{Cu}-\mathrm{K}_{\alpha 1}\right.$ radiation $\lambda=0.1542 \mathrm{~nm}$ at 40 $\mathrm{kV}$ and $30 \mathrm{~mA}$ ) instrument operated in Bragg-Brentano geometry with a step size of $0.005^{\circ}$ and a scan range from 10 to $100^{\circ}$. XRD measurements were performed on the surface of all the processed samples. The relative content of corundum phase $\left(\alpha-\mathrm{Al}_{2} \mathrm{O}_{3}\right)$ in the oxide layer was deduced from XRD peak adjustment and calculated from the integrated intensity of $\alpha$ $\mathrm{Al}_{2} \mathrm{O}_{3}$ peaks compared with the integrated ones of both $\alpha$ - and $\eta-\mathrm{Al}_{2} \mathrm{O}_{3}[45]$.

\subsection{PEO process characterization}

The light emitted by the micro-discharges (MDs) was detected with a Hamamatsu R928 photomultiplier whose output signal was amplified by a $300 \mathrm{MHz}$ bandwidth current amplifier (Standford Research Systems SR445). The photomultiplier signal, together with current and voltage waveforms, were collected and recorded using a $1 \mathrm{GHz}$ bandwidth oscilloscope (Agilent 54832B) over more than 20 periods of the current. As a complement, videos of the MDs during PEO processing were recorded using a Photron SA1.1 high speed camera, which allowed studying the MDs evolution with time. As depicted in previous Ref. [45], only the lower half-part of the sample is filmed over an area of $7.5 \mathrm{~cm}^{2}(30 \mathrm{~mm} \times 25$ 
$\mathrm{mm})$. For the present study, the sampling rate was set at 125,000 frames per second (125 kfps) which corresponds to a time resolution of $8 \mu$ s. Under these specific recording conditions, the spatial resolution of the camera was set at $0.017 \mathrm{~mm}^{2}$ which is at least three times lower than the average area of MDs that was detected in the experiments. Automatic image processing was done using the TRACE software to discriminate MDs and to follow some of their characteristics as a function of the processing time such as their spatial distribution, surface density (per unit time), lifetime $(\mu \mathrm{s})$ and size (cross-sectional area in $\mathrm{mm}^{2}$ ) [47-48].

\section{Experimental results}

\subsection{In situ characterization of the PEO process}

Fig. 1 shows the evolution of the anodic and the cathodic voltage amplitudes as a function of the processing time for the different RCQ investigated. The voltage-time responses of the PEO treatments reveal quite similar trends for all the investigated RCQ. In galvanostatic mode, as the PEO process starts, a sharp increase in the voltage occurs during the first seconds, which is then followed by a much reduced variation of the voltage-time curve. The anodic potential, at which slope changes, is designated as the sparking potential and is usually associated with the ignition of the first MDs over the processed surface $[2,16$, 40, 45]. Increasing the RCQ from 0.5 to 6.0 was found to result in higher anodic breakdown voltage from 625 to $652 \mathrm{~V}$, respectively. In the specific case of the lowest RCQ $=0.5$, a decrease in the anodic voltage amplitude is observed after $8 \mathrm{~min}$. Although this electrical behaviour can be interpreted as the occurrence of the "soft" regime, the fact remains that it do not results in the formation of a thick and homogeneous covering oxide layer as it will be shown below. However this specific electrical condition will be considered throughout the study because its contribution supports the proposed mechanism of charge accumulation which will be discuss hereinafter. 
Chronograms in Fig. 2 show the evolutions of the light emission as a function of the corresponding current and voltage signals recorded over $10 \mathrm{~ms}$ for the different RCQ investigated and after 1, 8 and 30 min of the process. First of all, MDs appear only during the anodic polarization. Such behaviour is usually encountered within the processing conditions used in this study. At the beginning of the treatment $(1 \mathrm{~min})$ and for all the different RCQ investigated, light emission exhibits quite the same behaviour since light emission is immediately detected when the pulse of the anodic current starts. It suggests that at the beginning of the process, the delay between the MDs appearance and the rising edge of the anodic current is almost null. However, after $8 \mathrm{~min}$ and depending on the value of the RCQ, light emission is detected after a few microseconds to a few hundreds of microseconds after the rising edge of the current. It appears that the delay in the MDs appearance is longer for lower RCQ. As the process goes on, the delay increases for all the RCQ investigated. At the end of the process $(30 \mathrm{~min})$, no light emission is detected for the lowest RCQ $=0.5$, which suggests an extinction of the MDs during the PEO treatment. Finally, concerning the voltagetime response, once the current starts, the increase in the voltage is not linear versus time. Moreover, the voltage-time response varies as the process goes on and it is strongly influenced by the value of the applied RCQ. Indeed, the increase in the voltage is slower for greater processing time and for lower RCQ. This point will be investigated in detail hereinafter.

Fig. 3 shows the evolution of the delay in the MDs appearance as a function of the processing time for the different RCQ that were investigated. As the process starts, Fig. 3 confirms that no delay is detected between light emission and the rising edge of the anodic current. At the end of the process (30 min), the highest delay, $2.06 \mathrm{~ms}$, is recorded for the sample processed with the intermediate $\mathrm{RCQ}=0.9$ while the lowest delay, $0.18 \mathrm{~ms}$, is obtained for the highest RCQ $=6.0$. Until the thirteenth minute of the process, the evolutions 
of the delay for the intermediate ratios $\mathrm{RCQ}=0.9,1.5,1.6$ follow a similar trend. After that, the delay increases almost linearly for $R=0.9$ while for the two other close ratios $R=1.5$ and 1.6, the delay stabilizes to an almost constant value at $0.8 \mathrm{~ms}$. In addition, Fig. 3 also evidences that in the specific case of the lowest RCQ $=0.5$, the delay increases rapidly with the processing time and extinction of the MDS occurs after 8 min, which coincides with the onset of the anodic voltage decrease observed in Fig. 1. It is also worth noting that evolutions of the delay between the RCQ $=1.5$ and 1.6 are close to each other even though they were obtained by varying two different parameters of the cathodic current waveform (see Fig. S1 in supplementary data). This confirms that RCQ is an important parameter in controlling the process.

Fig. S2 in supplementary data shows the spatial distribution of the MDs over the samples processed with various RCQ at various processing times (1, 8 and $30 \mathrm{~min})$. Each plot consists of an integration of the 475 processed images spanning over the anodic half period duration $(3.8 \mathrm{~ms})$. Regardless of the RCQ applied to the sample, the number of MDs that develop over the processed surface gradually decreases as the PEO process goes on. At the beginning of the process $(1 \mathrm{~min})$, MDs are numerous and they are preferentially located at the corners and at the edges of the sample, while from $8 \mathrm{~min}$ on, they gradually cover the centre of the sample leaving the corners and the edges depopulated. Parfenov et al. showed that this edge effect can be explained by considering the electric field distribution over the rectangular geometry of the sample, the strength of the electric field being stronger at corners than on a flat surface [49]. At the end of the process (30 min), MDs have completely disappeared from the surface of the sample processed with the lowest $\mathrm{RCQ}=0.5$ while they are more and more grouped together in some locations of the surface as the RCQ gets higher. This is particularly evident for the sample processed with the highest RCQ $=6.0$. A recent study by Nomine et al. evidence that MDs occur in "cascades" at specific locations over the processed surface during 
the anodic regime $[50,51]$. This seems to be in good agreement with Fig. S2 which also suggests that i) this mechanism of localized MDs appearance is accentuated as the process goes on and ii) the number of MDs involved at each particular location becomes higher for higher RCQ.

For the different RCQ values investigated, Fig. S3 in supplementary data depicts the evolution of some characteristics of the MDs as a function of the processing time such as their surface density (Fig. S3a), their average size (Fig. S3b) and their average lifetime (Fig. S3c). Whatever the RCQ used, the surface density at the beginning of the process (down to $1 \mathrm{~min}$ ) is high in a narrow range around $1000 \mathrm{~cm}^{-2} \cdot \mathrm{ms}^{-1}$. As the PEO process goes on, the surface density of MDs decreases by one order of magnitude to reach an almost constant low value around $100 \mathrm{~cm}^{-2} \cdot \mathrm{ms}^{-1}$ in the end. Except for the specific case of the lowest RCQ $=0.5$, where the MDs disappear after 8 min, the surface density of MDs decreases much faster as the RCQ gets higher. The surface density stabilizes at a constant low value $\sim 100 \mathrm{~cm}^{-2} \cdot \mathrm{ms}^{-1}$ after $\sim 5, \sim$ 17, $\sim 17$ and $\sim 30 \mathrm{~min}$ for the samples processed with ratio $R=6.0,1.6,1.5,0.9$, respectively. Then, during the entire course of the PEO process, the sample processed with the intermediate RCQ $=0.9$ undergoes much more MDs than the other samples. Fig. S3b shows that the average size of the MDs increases with the processing time and the RCQ. From $30 \mathrm{~s}$ to $\sim 9$ min, the mean size of the MDs increases gradually from $\sim 0.045$ to $\sim 0.060 \mathrm{~mm}^{2}$ and no difference is observed between the samples processed with different RCQ. After 9 min, the average size increases more rapidly for higher RCQ than for the lower ones. As the process approaches the end, at $25 \mathrm{~min}$, the average size is about $\sim 0.059 \mathrm{~mm}^{2}, \sim 0.078 \mathrm{~mm}^{2}, \sim 0.101$ $\mathrm{mm}^{2}$ and $\sim 0.140 \mathrm{~mm}^{2}$ at $R=0.9,1.5$ and 1.6 and 6.0, respectively. Thus, Fig. S3b evidences that large MDs are promoted at high RCQ while lower ratio results in smaller MDs. Fig. S3c shows that irrespective of the electrical conditions applied, the average lifetime of the MDs increases with the processing time. During the first minutes of treatment, from $30 \mathrm{~s}$ to $9 \mathrm{~min}$, 
no significant differences are observed between the different processed samples, the average lifetime increasing gradually from 22 to around $30 \mu$ s, respectively. Nevertheless significant deviations occur from the ninth minute since the average lifetime increases more rapidly for the higher RCQ than for the lower ones. At $25 \mathrm{~min}$, the longest average lifetime (49 $\mu \mathrm{s})$ was observed for the sample processed with the highest RCQ $=6.0$ while the shortest average lifetime $(34 \mu \mathrm{s})$ was measured for the sample processed with the intermediate ratio RCQ $=$ 0.9. Thus, Fig. S3c evidences that long-duration MDs are promoted at high RCQ. In addition, Fig. S3b and Fig. S3c show that the MDs characteristics in terms of size and lifetime are different between the samples processed with $\mathrm{RCQ}=1.5$ and 1.6. This is in constrast with the observations done on the MDs appearance (see Fig. 3) and surface density (see Fig. S3a). This means that the RCQ plays certainly a major role in the MDs ignition but the size and lifetime of the MDs seem to be more affected by the cathodic current amplitude $I_{c a t h}$ and duration $t_{\text {cath }}$. However, further works are needed to clearly decouple the respective influence of each waveform parameter on the MDs behaviour.

\subsection{Ex situ characterization of the PEO coatings}

Fig. 4 shows top-view and cross-section SEM micrographs of the PEO oxide layers grown for 30 min within the different RCQ. They were recorded at the centre of the samples. The surfaces exhibit the typical morphology of the PEO coatings consisting in a mixture of pancake-like structures surrounded by a sponge-like structure [24]. The pancake-like structure is the usual feature of PEO layers grown on aluminium substrates. It is associated with a discharge channel (5 - $30 \mu \mathrm{m}$ in diameter) usually localized at the centre of the "pancake" structure and is considered as an open pore. In contrast, the sponge-like structure known to incorporate elements from the electrolyte ( $\mathrm{Si}, \mathrm{Na}, \mathrm{K}$ for example) is characterized by thinner pores with diameters in the range of $0.1-1 \mu \mathrm{m}$. The topmost surfaces of the oxide 
coatings elaborated with RCQ higher than 1.5 are largely dominated by the pancake-like structure surrounded by a few sponge-like structures. In contrast, by applying the intermediate $\mathrm{RCQ}=0.9$, these large open pores disappear concomitantly with the disappearance of large discharge channels and the "sponges"-like structure is more developed and cover the whole processed surface. From the cross-section SEM micrographs, all the elaborated PEO coatings exhibit two distinct sublayers that are characteristics of PEO layers grown on aluminium alloy: an inner sublayer adjacent to the aluminium substrate which is recognizable from its thin pores (down to $1 \mu \mathrm{m}$ in diameter) homogeneously distributed throughout the layer and an outer sublayer that consists of cracked plates and large open pores (up to $10 \mu \mathrm{m}$ in diameter). In Fig. 5, the overall thickness is observed to be quite the same for all the processed samples: $\sim 82 \mu \mathrm{m}$ (except for RCQ $=0.5$ ). However, the proportion of each sublayer in the total coating thickness is strongly dependent on the RCQ. The presence of the outer sublayer with large open pores is promoted by high RCQ while low RCQ promote the thickening of the inner layer with thin porosity. For the highest $\mathrm{RCQ}=6.0$, the thickness of the inner sublayer is below $\sim 36 \mu \mathrm{m}$. In contrast, for the intermediate RCQ $=0.9$, the thickness of the inner sublayer is higher than $\sim 53 \mu \mathrm{m}$. Concerning the lowest RCQ $=0.5$ and even though the sample was also processed for $30 \mathrm{~min}$, the morphology of the topmost surface looks like as if it has been poorly processed. The oxide layer is thin and does not cover the metal surface homogeneously. At some locations over the processed surface, the oxide layer seems to have been removed.

Fig. S4 in supplementary data shows the X-ray diffraction patterns recorded on the PEO layers grown for 30 min with various RCQ. All coatings are predominantly composed of $\alpha$ and $\eta$ phases of crystalline alumina $\mathrm{Al}_{2} \mathrm{O}_{3}$. Note that the appearance of aluminium peaks is due to the diagnostic method based on the use of an incident X-ray beam that crosses the PEO coating and reaches the aluminium metallic substrate. As proposed by Xue et al. [6], the 
relative intensity of (113) $\alpha-\mathrm{Al}_{2} \mathrm{O}_{3}$ (at $\left.43.6^{\circ}\right)$ and (400) $\eta-\mathrm{Al}_{2} \mathrm{O}_{3}\left(\right.$ at $45.96^{\circ}$ ) peaks are used to estimate the relative $\alpha$ - and $\eta-\mathrm{Al}_{2} \mathrm{O}_{3}$ content in the oxide layer. Fig. S4b, which is a selected region of the XRD patterns in the range of $\left[42 ; 48^{\circ}\right]$, shows that such a relative intensity of the $\alpha$ - and $\eta-\mathrm{Al}_{2} \mathrm{O}_{3}$ peaks increases noticeably with the increase in the RCQ. This means that the proportion of the $\alpha-\mathrm{Al}_{2} \mathrm{O}_{3}$ phase increases at the expense of the $\eta$ phase as the RCQ gets higher. The relative content of the $\alpha-\mathrm{Al}_{2} \mathrm{O}_{3}$ phase in the overall coating has been quantified for samples processed with various RCQ. It is confirmed in Fig. S4c, which shows the variation of the calculated $\alpha-\mathrm{Al}_{2} \mathrm{O}_{3}$ content as a function of the RCQ. The $\alpha-\mathrm{Al}_{2} \mathrm{O}_{3}$ content increases with the RCQ. With the lowest $\mathrm{RCQ}=0.5$, the $\alpha-\mathrm{Al}_{2} \mathrm{O}_{3}$ content is about $5 \%$ while it reaches about $37 \%$ with the highest $\mathrm{RCQ}=6.0$. The $\alpha-\mathrm{Al}_{2} \mathrm{O}_{3}$ content abruptly increases from about $5 \%$ to about $35 \%$ when the RCQ increases from 0.5 to 1.6. Above RCQ $=1.5$, the $\alpha-\mathrm{Al}_{2} \mathrm{O}_{3}$ content stabilizes to an almost constant value at $37 \%$. For the intermediate RCQ $=0.9$, the $\alpha-\mathrm{Al}_{2} \mathrm{O}_{3}$ content takes an intermediate value at about $30 \%$.

\section{Discussion}

Fig. 6 is the schematic diagram of the proposed mechanism of charge accumulation which takes place at the oxide - electrolyte interface during pulsed bipolar PEO process of aluminium. This mechanism of charge accumulation which was experimentally evidenced by varying the RCQ is described over 1 pulse period of the current according to 3 subsequent stages : (i) in the course of the cathodic regime (stage 0 to stage 1), (ii) during the transition from the cathodic to the anodic regime (stage 1 to stage 2) and (iii) in the course of the anodic regime (stage 2 to stage 3). Effect of the RCQ on this mechanism is also illustrated in Fig. 6 by considering 3 extreme ranges of the RCQ: low RCQ $<<0.9$, intermediate RCQ $=0.9$ and high RCQ $>$ 0.9. In each case, a schematic morphology directly issued from the crosssection SEM micrographs in Fig. 4 is also considered: a thin oxide layer with thin open 
porosity for low RCQ $\ll 0.9$, a thick oxide layer with a network of thin porosities for intermediate RCQ $=0.9$ and a thick oxide layer with large open pores for high RCQ $>0.9$. To start the description of the proposed mechanism of charge accumulation and due to the basicity of the electrolyte $(\mathrm{pH}=12.5)$, it is assumed that the initial state of the description (referred to as stage 0 in Fig. 6) is characterized by the presence an excess of hydroxide anion $\mathrm{OH}^{-}$and a low proportion of proton ions $\mathrm{H}^{+}$at the vicinity of the electrolyte / oxide interface. Depending on the substrate bias polarization, cations $\left(\mathrm{H}^{+}\right)$and anions $\left(\mathrm{OH}^{-}\right)$are expected to be the most important species in terms of number density and mobility that can accumulate. When applying an external electric field, the ionic migration can be oriented in one direction or the other depending on the charge sign with respect to the direction of the applied electric field.

\subsection{In the course of the cathodic regime}

In the course of the cathodic regime (from stage 0 to stage 1 in Fig. 6), the processed substrates are negatively biased. The direction of the cathodic electric field is oriented locally from the electrolyte to the substrate. As a consequence, negative charges, in particular hydroxide anions $\mathrm{OH}^{-}$, are extracted from the electrolyte / coating interface towards the surrounding electrolyte while positive charges, mainly the proton cations $\mathrm{H}^{+}$move towards the electrolyte / coating interface. It would be reasonable to expect that the magnitude of such a negative charge extraction process is strongly dependent on the duration $t_{c a t h}$ and current amplitude $I_{\text {cath. }}$ of the cathodic regime (schematically represented by a more or less large arrow of the electric field in Fig. 6). In the case of low RCQ for which a strong cathodic regime holds (high amplitude and/or long duration of the cathodic current), the dynamic of the extraction process is strong and the negative charges are repelled far from the electrolyte / coating interface. This results in a large double layer which separates $\mathrm{OH}^{-}$anions and $\mathrm{H}^{+}$ cations. In contrast, this extraction of anionic charges from the interface is much more limited 
with higher RCQ, negative charges remaining therefore closer to the electrolyte / coating interface. In this case, the formed double layer is therefore very thin. For RCQ $=0.9$, the extraction process of the negative charges is moderate which leads to the formation of an intermediate double layer. Following this mechanism, at the end of the cathodic half-period, the density of charges accumulated at the vicinity of the electrolyte / coating interface is directly affected by the magnitude of the cathodic phenomena that occurred just before, the density of $\mathrm{OH}$ - ions remaining high when the charge transport was limited. Such differences have crucial effects on the subsequent anodic regime and as a consequence on both the MDs behaviour and the PEO oxide layers.

\subsection{Transition from the cathodic to the anodic regime}

As the current polarity switches from negative to positive values (from stage 1 to stage 2 in Fig. 6), the direction of the applied electric field is reversed. Therefore negative charges, $\mathrm{SiO}_{3}{ }^{2-}$ and mainly $\mathrm{OH}^{-}$anions, are now attracted towards the electrolyte / coating interface while positive charges, mainly $\mathrm{Na}^{+}$cations, move far from this interface toward the bulk electrolyte. For the sample processed with high RCQ $\gg 0.9$, the dynamic of the charge accumulation at this interface is strong. Indeed, $\mathrm{OH}^{-}$charges which stayed close to the oxide coating at the end of the prior low cathodic half period, move rapidly through the thin double layer and reach rapidly the oxide interface. As a consequence, once the anodic current starts to increase, the value of the local electric field reaches rapidly the breakdown field value of the oxide layer. This explains why the delay of the MDs ignition is short for high RCQ > 0.9 (see Fig. 2 and Fig. 3). In addition, it is also worth considering that accumulation of charges takes place at certain insulating zones of the oxide, where the matter is dense and the electrical conductivity is low. In contrast, the accumulation of charges in open pores is lower due to the presence of the conductive electrolyte that fills the pores. For high RCQ >> 0.9 , the ratio of areas of dense oxide where the accumulation proceeds to the total sample area 
is considerably reduced because of large discharge channels and large open pores that are observed all over the surface. Consequently, the MDs number density is small (Fig. S3a) and these MDs are grouped together in bundles at given locations on the surface (Fig. S2). There, the mechanism of charge accumulation is locally so strong that dielectric breakdown is associated to MDs with high intensity which are known to cause local damage to the PEO oxide layer. This is in good agreement with the experimental results on MDs and on the elaborated oxide layers, which evidences that high RCQ >> 0.9 promote long-life and largesize MDs (Figs. 6b-c). This results in the formation of large discharge channels and the development of large open porosity (Fig. 4 and Fig. 5). The increase in the $\alpha-\mathrm{Al}_{2} \mathrm{O}_{3}$ content in the oxide coating coincides with the use of high RCQ and the occurrence of intense MDs (Fig. S4). It is reasonable to claim that the thermal heating enhanced by these powerful MDs promote the $\eta-\rightarrow \alpha-\mathrm{Al}_{2} \mathrm{O}_{3}$ phase transition from the wall of the discharge channels inwards. Inversely, for the sample processed with intermediate $\mathrm{RCQ}=0.9$, the dynamic of the anionic charge accumulation at the electrolyte / coating interface is much more moderate. This can be explained by the joined effects of a high extraction of electric charges occurring in the course of the prior cathodic regime and a high dissipation of electric charges through the network of the thin porosity filled with electrolyte. Consequently, once the current starts, the local electric field throughout the oxide coating has not yet reached its breakdown value. This is evidenced experimentally by the fact that MDs are delayed with respect to the rising edge of the anodic current (See Fig. 2 and Fig. 3). Such a delay corresponds to the required period during which the value of the breakdown field of the as-formed dielectric layer is locally reached. Concerning the particular case of low RCQ $<<0.9$, and for similar reasons as those described for the intermediate RCQ $=0.9$, the mechanism of charge extraction that occurs during the previous cathodic half period is so strong that no sufficient anionic charges are 
accumulated at the electrolyte / oxide interface during the subsequent rise of the anodic current pulse and no MDs appear.

\subsection{In the course of the anodic regime}

In the course of the anodic regime (from stage 2 to stage 3 in Fig. 6) and whatever the electrical condition applied to the processed samples, accumulation of $\mathrm{OH}^{-}$ions goes on at the electrolyte / coating interface. For samples processed with high RCQ > 0.9, the layer breakdown that took place earlier in the anodic regime induced a local contact between the metallic electrode and the electrolyte. A large amount of anionic charges accumulated close to the discharge channel flows therefore through the channel, oxide locally the aluminium metallic substrate and thus limits locally further charge accumulation. The next dielectric breakdown of the oxide layer has therefore a low probability to occur in the vicinity of the formerly-created open channel. Consequently, because coatings elaborated at high RCQ present numerous large open pores that behave as shortcuts, the new charge accumulation holds at other dense and thick locations over the processed surface, far from the aforementioned discharge channels. This explains that MDs do not cover the processed surface homogeneously and are more localized at some spots of the surface with higher RCQ (Fig. S2 in supplementary data). At these new unaffected locations, until the end of the anodic half-period, the dynamic of the anions accumulation continues to be high and MDs that are ignited follow the similar detrimental behaviour that has been described in the previous part. In the case of the sample processed with intermediate RCQ $=0.9$, for which the breakdown value of the as-formed coating could not be reached during the first step of the anodic alternation, the two mechanisms of negative charge accumulation and charge dissipation through thin pores continue in the course of the anodic regime. At this point, it is worth noting that although pores are thin in the oxide layer, they are quite homogeneously distributed throughout the coating thickness and the level of porosity remains high (Fig. 4). This implies 
that walls of dense oxide, localized between adjacent pores, are numerous and thin. In the course of the anodic regime, electric charges accumulated on both sides of such walls reach the breakdown electric field and MDs appear. Because thickness of oxide walls is thin, the required charges to induce breakdown is low. Consequently, in the case of the samples processed with intermediate $\mathrm{RCQ}=0.9$, it would be reasonable to expect MDs to be and follow a smooth behaviour which is known to have a beneficial effect on the growing oxide coating. This assumption is in good agreement with experimental results on both MDs and the as-grown oxide coating. Indeed, results evidenced that MDs exhibit the smallest size and the shortest lifetime and they are quite homogenously distributed over the processed surface (See Fig. S2 and Fig. S3 in supplementary data). SEM observations showed that within such a soft MDs regime, the morphology of the resulting oxide layer is improved. Oxide layer is thicker, covers homogeneously the metal and the coating - substrate interface is smoother (Fig. 4). It is also worth noting that the moderate content of the $\alpha-\mathrm{Al}_{2} \mathrm{O}_{3}$ phase in the oxide coating can be related to the moderate intensity of the MDs that induces a limited local heating of the oxide layer (Fig. S4). In the critical case of the sample processed with very low RCQ $<<0.9$, extraction of electric charges occurs far away from the electrolyte - coating interface during the prior cathodic half period. The magnitude of this phenomenon is so high that the subsequent process of anionic charge accumulation at the electrolyte / oxide interface is made inefficient during the subsequent anodic polarization. The dielectric breakdown value of the thin oxide layer is therefore difficult to reach in the course of the anodic half-period. As a result, very few, if not none, MDs are expected to occur over the processed surface. This assumption was experimentally verified since extinction of MDs discharge is observed after 8 min (Fig. 3). The fact that MDs stop definitively suggests that the mechanism of charge accumulation taking place during the anodic regime does not compensate for the effects of charge extraction during the prior cathodic regime. As a consequence, no visible MDs are 
ignited over the processed surface and the growth of the protective oxide coating is therefore inhibited and stopped. It is consistent with the fact that, for low RCQ $\ll<0.9$, the processed sample appears as shortly processed, or even unprocessed at some locations (Fig. 4).

\subsection{Evidence of the capacitive behaviour of the PEO oxide layer}

The proposed mechanism of charge accumulation that takes place before dielectric breakdown, and thus before MDs, is related to the capacitive behaviour of the growing PEO oxide layer. The evidence of this capacitive behaviour can be revealed from the close analysis of the voltage-time response of the electrolyser system, which is composed of the electrolyte / oxide / metal stack. Whatever the applied conditions, chronograms in Fig. 2 clearly show that the voltage signal exhibits a transient regime during the first milliseconds after the start of the anodic polarization. One example of anodic voltage-time response is depicted in more detail in Fig. 7. The experimental data of the anodic voltage can be adequately fitted by the exponential decay function of Eq. (1):

$u=u_{\max }\left(1-e^{-\frac{t}{\tau}}\right)$

Table 2 reports some results of the fitting procedure performed at various processing time (1, 8 and $30 \mathrm{~min}$ ) for the different RCQ investigated. Fit of the experimental data with Eq. (1) gives access to the amplitude of the anodic voltage $u_{\max }$ for which the permanent regime is reached and also to the time constant $\tau$ of the transient regime. The time constant $\tau$ could be interpreted as the characteristic duration during which the accumulated charges at the oxide interfaces are sufficiently numerous to cause dielectric breakdown. From Table 2 and Fig. 8, it can be seen that the time constant increases gradually with the processing time. After about ten minutes and except for the sample processed with $\mathrm{RCQ}=0.5$ for which $\tau$ falls after 8 min, this time constant remains constant and is clearly higher for lower RCQ. 
Previous works from Gao et al. [52] and Fatkullin et al. [53] propose a simplest equivalent $\mathrm{RC}$ circuit to describe the relaxation of the PEO electrolyser system during the anodic voltage pulse-off period which includes capacitor discharging. In this work, which is focused on the voltage-time response during the voltage pulse-on period, one can also considers a simplest equivalent RC circuit supplied by a current generator to describe the voltage-time response of the electrolyser system. This circuit is given in Fig. 9a and it consists in the electrolyte resistance $\mathrm{R}_{\mathrm{el}}$ in series with the parallel combination of the oxide coating resistance $\mathrm{R}_{\mathrm{ox}}$ and its capacitance $\mathrm{C}_{\mathrm{ox}}$ for which the voltage-time response follows Eq. (2):

$u=\left(R_{e l}+R_{o x}\left(1-e^{-\frac{t}{\tau}}\right)\right) \cdot i$

Resistance of the electrolyte $\mathrm{R}_{\mathrm{el}}=4 \pm 1 \Omega$, assumed constant in time and for the different processing conditions used, was calculated by solving Eq. (3), which involves the aluminium / counter-electrodes distance $(\mathrm{D}=9 \mathrm{~cm})$, the electrolyte conductivity $\left(\sigma_{\mathrm{el}}=4 \times 10^{-3}{\mathrm{~S} . \mathrm{cm}^{-1}}^{-1}\right)$ and the cross-section area of the current flow between the aluminium and the counter-electrodes $\left(\mathrm{S}=255 \mathrm{~cm}^{2}\right)$.

$R_{e l}=\frac{D}{\sigma_{e l} \cdot S}$

Then, from the identification of terms between the fitted voltage-time response in Eq. (1) and the voltage-time response of the proposed equivalent RC circuit in Eq. (2), the oxide layer resistance $\mathrm{R}_{\mathrm{ox}}$ and its capacitance $\mathrm{C}_{\mathrm{ox}}$ can be calculated thanks to Eq.(4) and Eq. (5), respectively.

$R_{o x}=\frac{u_{\max }-R_{e l} . i}{i}$

$C_{o x}=\frac{\tau}{R_{o x}}$ 
The oxide layer resistance $R_{\mathrm{ox}}$ is related to the thickness of the oxide layer and also to the permeability of the oxide coating to the conductive electrolyte. The oxide layer capacitance $\mathrm{C}_{\mathrm{ox}}$ is usually associated with the surface area available for the electric charge storage. Particularly for PEO oxide coatings, which exhibit a high porosity level, the oxide capacitance is directly associated with the specific surface area of pores. Table 3 gives the circuits parameters $R_{o x}$ and $C_{o x}$ determined at various processing time (1,8 and $30 \mathrm{~min}$ ) for the different RCQ investigated. The evolution of $\mathrm{R}_{\mathrm{ox}}$ and $\mathrm{C}_{\mathrm{ox}}$ with processing time is shown in Fig. 9a and b, respectively. After the start of the PEO process, $\mathrm{R}_{\mathrm{ox}}$ and $\mathrm{C}_{\mathrm{ox}}$ increase with time. This mainly reflects the gradual thickening of the oxide layer and the gradual development of thin pores through the thickness, respectively. From about 10 minutes, although the oxide resistance still increases with time (except in the specific case of the sample processed with RCQ $=0.5$ ), the oxide capacitance tends to stabilize at a constant value (depends on the applied RCQ) until the end of the process. It means that the gradual thickening of the PEO oxide layer continues after about 10 minutes while the density of thin pores that store charges through the oxide layer remains constant as the process goes on. This is in good agreement with the morphology of the elaborated oxide layers observed in Fig. 4 and measurements in Fig. 5. The fact that the capacitive behaviour is higher for the intermediate RCQ $=0.9$ is explained by the formation of a thicker oxide layer, completely filled by a network of thin pores (Fig. 5). In contrast, the capacitive behaviour is the lowest for the oxide layer formed under the highest $\mathrm{RCQ}=6.0$ because the overall oxide layer consists mainly in large open pores for which the specific surface area necessary to store charges is lower than numerous and fine pores (Fig. 5). In the specific case of the sample processed under the lowest RCQ = 0.5 , the time constant decreases distinctly at 8 min mainly because of the sharp decrease in the oxide resistance. It suggests that during the first minutes of the treatment, an oxide layer grow up over the metal substrate, this layer becoming gradually thinner and less impermeable to the 
electrolyte after $8 \mathrm{~min}$. This is in good agreement with cross-section micrograph in Fig. 4 where the presence of a very thin and a porous oxide layer which even seems does not cover the metal substrate at some locations is observed. Within the lowest RCQ $=0.5$ and due to the associated large amount of cathodic polarization, a mechanism of corrosion which starts to overcome the protective effect of the metal oxidation cannot be excluded, even though no clear evidence of corrosion has been detected.

Fig. 10 plots the different delays of the light emission that were measured in this study as a function of the time constants of the transient regime of the voltage-time responses. The delay of the light emission, deduced from experimental measurements, corresponds to the duration beyond which MDs appear while the time constant $\tau$, deduced from the simulation of the electrolyser-time response, could be interpreted as the minimum duration required to accumulate the sufficient electrical charges beyond which the dielectric breakdown of the oxide layer occurs. A linear correlation is found for low delay, which evidences that the main mechanism inducing the MDs ignition is the proposed mechanism of charge accumulation. Nevertheless, it appears that after a certain delay, depending on the RCQ used, the time constant remains constant while the delay in the MDs appearance still increases. Even if this point should be the object of further investigations, we propose to explain it by the development of inner MDs through thin pores before the appearance of external (i.e. visible) MDs. For short treatment times for which the delays of MDs appearance are shorter, the good correlation with the time constant means that accumulation of charge throughout the oxide layer is the main mechanism responsible for the dielectric breakdown of the oxide layer and thus the MDs appearance. For longer processing time, as the time constant $\tau$ remains constant while the delay in MDs still increases, we infer that the gradual development of thin pores into the oxide tends to gradually promote the development of inner and not detectable MDs through the pore network. The presence of internal MDs, already discussed in literature but 
never experimentally highlighted, will have to receive a particular attention in the future, especially to explain the growth of PEO oxide layers elaborated under the "soft"-regime where MDs are no longer visible over the sample.

\section{Conclusion}

The influence of the cathodic regime on the pulsed bipolar PEO of a 2214 aluminium alloy has been investigated. Various ratios of charge quantity RCQ $=Q_{p} / Q_{n}$ (defined as the ratio between the anodic $Q_{p}$ to cathodic $Q_{n}$ charge quantity) in the range [0.5 - 6.0] were investigated by changing only the magnitude of cathodic regime.

a) Results show that occurrence of micro-discharges (MDs) is delayed with respect to the rising edge of the anodic current. By applying too low RCQ $=0.5$, ignition of MDs is highly delayed (1.11 $\mathrm{ms}$ at $8 \mathrm{~min})$ and progressively inhibited in the course of the process. With intermediate $R C Q=0.9$, the delay is also high $(2.06 \mathrm{~ms}$ at $30 \mathrm{~min})$ and no extinction was observed until the end. The delay is the lowest for the highest RCQ $(0.18 \mathrm{~ms}$ at $30 \mathrm{~min}$ for $R=6.0$ ).

b) Results evidence that the behaviour of the MDs is affected by the RCQ used. It has been found that size and lifetime of MDs increase with the increase in the RCQ. By using the intermediate $\mathrm{RCQ}=0.9$, even though $\mathrm{MDs}$ remain numerous over the processed surface, they are homogeneously distributed and exhibit small size and short lifetime $\left(\sim 0.059 \mathrm{~mm}^{2}\right.$ average size and $\sim 34 \mu$ s average lifetime at $25 \mathrm{~min}$ ). In contrast, by applying higher RCQ, MDs are bigger and present longer lifetime $\left(\sim 0.140 \mathrm{~mm}^{2}\right.$ average size and $\sim 49 \mu$ s average lifetime at $25 \min$ for $R=6.0$ ).

c) Results show that characteristics of the as-formed oxide coating depend on the RCQ used. Results indicate that using the intermediate $\mathrm{RCQ}=0.9$ results in the formation of a thick oxide layer with thin pores. By using too low $\mathrm{RCQ}=0.5$, the processed sample appears as 
if shortly processed, or seems even corroded locally. The use of high RCQ $>0.9$ results in oxide layers with large open pores.

d) Fourthly, a mechanism of electrical charge accumulation taking place at the electrolyte / coating / substrate system until dielectric breakdown occurs is proposed to explain the collected results from the in situ process characterisation and from the ex situ PEO oxide layers characterization. The close correlation established between the delay in the MDs appearance with respect to the current and the time constant of the transient regime of the anodic voltage-time response supports the proposed mechanism of charge accumulation which takes place at the electrolyte / oxide interface.

\section{Acknowledgements}

We greatly acknowledge the Conseil Régional de Lorraine for granting A. Nominé's PhD work under decision 11CP-769. This work was supported by the French Government through the program "investissements d'avenir" operated by the French National Research Agency (ANR) and referenced to as ANR-11-LABX-0008-01 (LabEx DAMAS). 


\section{List of references}

[1] A.L. Yerokhin, X. Nie, A. Leyland, A. Matthews, S.J. Dowey, Plasma electrolysis for surface engineering, Surf. Coat. Technol. 122 (1999) 73-93.

[2] P. Bala Srinivasan, J. Liang, R.G. Balajeee, C. Blawert, M. Störmer, W. Dietzel, Effect of pulse frequency on the microstructure, phase composition and corrosion performance of a phosphate-based plasma electrolytic oxidation coated AM50 magnesium alloy, Appl. Surf. Sci. 256 (2010) 3928-3935.

[3] F. Monfort, A. Berkani, E. Matykina, P. Skeldon, G.E. Thompson, H. Habazaki, K. Shimizu, A Tracer Study of Oxide Growth during Spark Anodizing of Aluminum, J. Electrochem. Soc. 152 (2005) C382-C387.

[4] E. Matykina, A. Berkani, P. Skeldon, G.E. Thompson, Real-time imaging of coating growth during plasma electrolytic oxidation of titanium, Electrochim. Acta 53 (2007) 19871994.

[5] A.A. Voevodin, A.L. Yerokhin, V.V. Lyubimov, M.S. Donley, J.S. Zabinski, Characterization of wear protective AlSiO coatings formed on Al-based alloys by micro-arc discharge treatment, Surf. Coat. Technol. 86-87 (1996) 516-521.

[6] W. Xue, Z. Deng, Y. Lai, R. Chen, Analysis of Phase Distribution for Ceramic Coatings Formed by Microarc Oxidation on Aluminum Alloy, J. Am. Ceram. Soc. 81 (1998) 13651368.

[7] L.R. Krishna, A.S. Purnima, G. Sundararajan, A comparative study of tribological behavior of microarc oxidation and hard-anodized coatings, Wear 261 (2006) 1095-1101.

[8] J.A. Curran, H. Kalkanci, Yu. Magurova, T.W. Clyne, Mullite-rich plasma electrolytic oxide coatings for thermal barrier applications, Surf. Coat. Technol. 201 (2007) 8683-8687.

[9] K. Tillous, T. Toll-Duchanoy, E. Bauer-Grosse, L. Hericher, G. Geandier, Microstructure and phase composition of microarc oxidation surface layers formed on aluminium and its alloys 2214-T6 and 7050-T74, Surf. Coat. Technol. 203 (2009) 2969-2973.

[10] E. Arslan, Y. Totik, E.E. Demirci, Y. Vangolu, A. Alsaran, I. Efeoglu, High temperature wear behavior of aluminum oxide layers produced by AC micro arc oxidation, Surf. Coat. Technol. 204 (2009) 829-833.

[11] A.L. Yerokhin L.O. Snizhko, N.L. Gurevina, A. Leyland, A. Pilkington, A. Matthews, Discharge characterization in plasma electrolytic oxidation of aluminium, J. Phys. D: Appl. Phys. 36 (2003) 2110-2120. 
[12] A.L. Yerokhin L.O. Snizhko, N.L. Gurevina, A. Leyland, A. Pilkington, A. Matthews, Spatial characteristics of discharge phenomena in plasma electrolytic oxidation of aluminium alloy, Surf. Coat. Technol. 177-178 ( 2004) 779-783.

[13] C.S. Dunleavy, I.O. Golosnoy, J.A. Curran, T.W. Clyne, Characterisation of discharge events during plasma electrolytic oxidation, Surf. Coat. Technol. 203 (2009) 3410-3419.

[14] C.S. Dunleavy, J.A. Curran, T.W. Clyne, Self-similar scaling of discharge events through PEO coatings on aluminium, Surf. Coat. Technol. 206 (2011) 1051-1061.

[15] C.S. Dunleavy, J.A. Curran, T.W. Clyne, Time dependent statistics of plasma discharge parameters during bulk AC plasma electrolytic oxidation of aluminium, Appl. Surf. Sci. 268 (2013) 397-409.

[16] L.O. Snizhko, A.L. Yerokhin, A. Pilkington, N.L. Gurevina, D.O. Misnyankin, A. Leyland, A. Matthews, Anodic processes in plasma electrolytic oxidation of aluminium in alkaline solutions, Electrochim. Acta 49 (2004) 2085-2095

[17] H. F. Guo, M.Z. An, H.B. Huo, S. Xu, L.J. Wu, Microstructure characteristic of ceramic coatings fabricated on magnesium alloys by micro-arc oxidation in alkaline silicate solution, Appl. Surf. Sci 252 (2006) 7911-7916

[18] Q. Cai, L. Wang, B. Wei, Q. Liu, Electrochemical performance of microarc oxidation films formed on AZ91D magnesium alloy in silicate and phosphate electrolytes, Surf. Coat. Technol. 200 (2006) 3727-3733.

[19] C. Blawert, V. Heitmann, W. Dietzel, H.M. Nykyforchyn, M. Klapkiv, Influence of electrolyte on corrosion properties of plasma electrolytic conversion coated magnesium alloys, Surf. Coat. Technol. 201 (2007) 8709-8714.

[20] J. Liang, P. Bala Srinivasan, C. Blawert, M. Störmer, W. Dietzel, Electrochemical corrosion behaviour of plasma electrolytic oxidation coatings on AM50 magnesium alloy formed in silicate and phosphate based electrolytes, Electrochim. Acta 54 (2009) 3842-3850.

[21] Y. Cheng, F. Wu, J. Dong, X. Wu, Z. Xue, E. Matykina, P. Skeldon, G.E. Thompson, Comparison of plasma electrolytic oxidation of zirconium alloy in silicate- and aluminatebased electrolytes and wear properties of the resulting coatings, Electrochim. Acta 85 (2012) 25-32.

[22] A.L. Yerokhin, A. Shatrov, V. Samsonov, P. Shashkov, A. Pilkington, A. Leyland, A. Matthews, Oxide ceramic coatings on aluminium alloys produced by a pulsed bipolar plasma electrolytic oxidation process, Surf. Coat. Technol. 199 (2005) 150-157. 
[23] F. Jaspard-Mécuson, T. Czerwiec, G. Henrion, T. Belmonte, L. Dujardin, A. Viola, J. Beauvir, Tailored aluminium oxide layers by bipolar current adjustment in the Plasma Electrolytic Oxidation (PEO) process, Surf. Coat. Technol. 201 (2007) 8677-8682.

[24] E. Matykina, R. Arrabal, P. Skeldon, G.E. Thompson, Investigation of the growth processes of coatings formed by AC plasma electrolytic oxidation of aluminium, Electrochim. Acta 54 (2009) 6767-6778.

[25] E.V. Parfenov, A. Yerokhin, A. Matthews, Small signal frequency response studies for plasma electrolytic oxidation, Surf. Coat. Technol. 203 (2009) 2896-2904.

[26] P. Bala Srinivasan, J. Liang, R.G. Balajeee, C. Blawert, M. Störmer, W. Dietzel, Effect of pulse frequency on the microstructure, phase composition and corrosion performance of a phosphate-based plasma electrolytic oxidation coated AM50 magnesium alloy, Appl. Surf. Sci. 256 (2010) 3928-3935.

[27] A. Melhem, G. Henrion, T. Czerwiec, J.L. Briançon, T. Duchanoy, F. Brochard, T. Belmonte, Changes induced by process parameters in oxide layers grown by the PEO process on Al alloys, Surf. Coat. Technol. 205 (2011) S133-S136.

[28] R.O. Hussein, D.O. Northwood, X. Nie, The influence of pulse timing and current mode on the microstructure and corrosion behaviour of a plasma electrolytic oxidation (PEO) coated AM60B magnesium alloy, J. Alloys Comp. 541 (2012) 41-48.

[29] J. Martin, A. Melhem, I. Shchedrina, T. Duchanoy, A. Nominé, G. Henrion, T. Czerwiec, T. Belmonte, Effects of electrical parameters on plasma electrolytic oxidation of aluminium, Surf. Coat. Technol. 221 (2013) 70-76.

[30] M.D. Klapkiv, State of an electrolytic plasma in the process of synthesis of oxides based on aluminum, Mater. Sci. 31 (1996) 494-499.

[31] M.D. Klapkiv, Simulation of synthesis of oxide-ceramic coatings in discharge channels of a metal-electrolyte system, Mater. Sci. 35 (1999) 279-283.

[32] G. Sundararajan, L. Rama Krishna, Mechanisms underlying the formation of thick alumina coatings through the MAO coating technology, Surf. Coat. Technol. 167 (2003) 269277.

[33] L.R. Krishna, A.S. Purnima, N.P. Wasekar, G. Sundararajan, Kinetics and Properties of Micro Arc Oxidation Coatings Deposited on Commercial Al Alloys, Metall. Mater. Trans. A 38 (2007) 370-378.

[34] A.L. Yerokhin, V.V. Lyubimov, R.V. Ashitkov, Phase formation in ceramic coatings during plasma electrolytic oxidation of aluminium alloys, Ceram. Int. 24 (1998) 1-6. 
[35] E. Matykina, R. Arrabal, D.J. Scurr, A. Baron, P. Skeldon, G.E. Thompson, Investigation of the mechanism of plasma electrolytic oxidation of aluminium using ${ }^{18} \mathrm{O}$ tracer, Corrosion Sci. 52 (2010) 1070-1076.

[36] R.O. Hussein, X; Nie, D.O. Northwood, A. Yerokhin, A. Matthews, Spectroscopic study of electrolytic plasma and discharging behaviour during the plasma electrolytic oxidation (PEO) process, J. Phys. D.: Appl. Phys. 43 (2010) 105203.

[37] R.O. Hussein, X. Nie, D.O. Northwood, An investigation of ceramic coating growth mechanisms in plasma electrolytic oxidation (PEO) processing, Electrochim. Acta 112 (2013) 111-119.

[38] J. Jovović, S. Stojadinović, N.M. Šišović, N. Konjević, Spectroscopic characterization of plasma during electrolytic oxidation (PEO) of aluminium, Surf. Coat. Technol. 206 (2011) 24-28.

[39] V. Dehnavi, B.L. Luan, D.W. Shoesmith, X.Y. Liu, S. Rohani, Effect of duty cycle and applied current frequency on plasma electrolytic oxidation (PEO) coating growth behaviour, Surf. Coat. Technol. 226 (2013) 100-107.

[40] Y. Cheng, F. Wu, E. Matykina, P. Skeldon, G.E. Thompson, The influences of microdischarge types and silicate on the morphologies and phase compositions of plasma electrolytic oxidation coatings on Zircaloy-2, Corros. Sci. 59 (2012) 307-315.

[41] Y. Cheng, Z. Xue, Q. Wang, X. Wu, E. Matykina, P. Skeldon, G.E. Thompson, New findings on properties of plasma electrolytic oxidation coatings from study of an $\mathrm{Al}-\mathrm{Cu}-\mathrm{Li}$ alloy, Electrochim. Acta 107 (2013) 358-378.

[42] Y. Cheng, M. Mao, J. Cao, Z. Peng, Plasma electrolytic oxidation of an Al-Cu-Li alloy in alkaline aluminate electrolytes: A competition between growth and dissolution for the initial ultra-thin films, Electrochim. Acta 138 (2014) 417-429.

[43] R. Arrabal, E. Matykina, T. Hashimoto, P. Skeldon, G.E. Thompson, Characterization of AC PEO coatings on magnesium alloys, Surf. Coat. Technol. 203 (2009) 2207-2220.

[44] A. Mehlem, Ph.D. thesis, Institut National Polytechnique de Lorraine, Nancy, France, 2009 (in French)

[45] J. Martin, P. Leone, A. Nominé, D. Veys-Renaux, G. Henrion, T. Belmonte, Influence of electrolyte ageing on the Plasma Electrolytic Oxidation of aluminium, Surf. Coat. Technol. 269 (2015) 36-46.

[46] J. Beauvir, Patent WO 01/81658 A1 (2001). 
[47] S. Bardin, J-L. Briançon, F. Brochard, V. Martin, Y. Zayachuk, R. Hugon, J. Bougdira, Investigating Transport of Dust Particles in Plasmas, Contrib. Plasma Phys. 51 (2011) 246251.

[48] N. Endstrasser, F. Brochard, V. Rohde, M. Balden, T. Lunt, S. Bardin, J.-L. Briançon, R. $\mathrm{Neu}$, Video tracking and post-mortem analysis of dust particles from all tungsten ASDEX Upgrade, J. Nucl. Mater. 415 ( 2011) S1085-S1088.

[49] E.V. Parfenov, A. Yerokhin, R.R. Nevyantseva, M.V. Gorbatkov, C.-J. Liang, A. Matthews, Towards smart electrolytic plasma technologies: An overview of methodological approaches to process modelling, Surf. Coat. Technol. 269 (2015) 2-22.

[50] A. Nominé, S.C. Troughton, A.V. Nominé, G. Henrion, T.W. Clyne, High speed video evidence for localised discharge cascades during plasma electrolytic oxidation, Surf. Coat. Technol. 269 (2015) 125-130.

[51] S.C. Troughton, A. Nominé, J. Dean, T.W. Clyne, Effect of individual discharge cascades on the microstructure of plasma electrolytic oxidation coatings, Appl. Surf. Sci. 389 (2016) 260-269.

[52] Y. Gao, A. Yerokhin, E. Parfenov, A. Matthews, Application of Voltage Pulse Transient Analysis during Plasma Electrolytic Oxidation for Assessment of Characteristics and Corrosion Behaviour of $\mathrm{Ca}$ - and P-containing Coatings on Magnesium, Electrochim.Acta (2014) 218-230.

[53] A.R. Fatkullin, E.V. Parfenov, A. Yerokhin, D.M. Lazarev, A. Matthews, Effect of positive and negative pulse voltages on surface properties and equivalent circuit of the plasma electrolytic oxidation process, Surf. Coat. Technol. 284 (2015) 427-437. 


\section{List of tables}

Table 1: Pulse parameters for PEO of Al. (Anodic pulse waveform is kept unchanged, $\left.\mathrm{Q}_{\mathrm{p}}=62 \pm 2 \mathrm{C}, \mathrm{t}_{\text {anod. }}=4 \mathrm{~ms}, \mathrm{I}_{\text {anod. }}=20 \pm 0.5 \mathrm{~A}\right)$

\begin{tabular}{cccc}
\hline $\begin{array}{c}\text { Ratio of charge } \\
\text { quantity } R C Q=Q_{p} / Q_{n}\end{array}$ & $\begin{array}{c}\text { Cathodic charge } \\
\text { quantity } Q_{n}(C)\end{array}$ & $\begin{array}{c}\text { Cathodic pulse } \\
\text { duration } t_{\text {cat. }}(\mathrm{ms})\end{array}$ & $\begin{array}{c}\text { Cathodic pulse } \\
\text { current } I_{\text {cath. }}(\mathrm{A})\end{array}$ \\
\hline $\mathbf{0 . 5}$ & 123.0 & 6 & -21 \\
$\mathbf{0 . 9}$ & 68.5 & 6 & -12 \\
$\mathbf{1 . 5}$ & 41.0 & 6 & -7 \\
$\mathbf{1 . 6}$ & 38.5 & 3.5 & -12 \\
$\mathbf{6 . 0}$ & 10.3 & 1.2 & -12 \\
\hline
\end{tabular}

Table 2: Approximation parameters $\left(\mathrm{u}_{\max }\right.$ and $\left.\tau\right)$ of the transient voltage recorded at different processing times (1, 8 and $30 \mathrm{~min}$ ) during PEO of $\mathrm{Al}$ in various RCQ conditions $(0.5,0.9,1.5$, 1.6 and 6.0). The transients have been approximated by a non-linear squares method using the Eq. (1).

\begin{tabular}{ccccccc}
\hline RCQ & Proc. Time (min) & $u_{\max }(\mathrm{V})$ & $\Delta \mathrm{u}_{\max }(\mathrm{V})$ & $\tau\left(\times 10^{-4} \mathbf{s}\right)$ & $\Delta \tau\left(\times 10^{-5} s\right)$ & $R^{\mathbf{2}}$ \\
\hline $\mathbf{0 . 5}$ & 1 & 656 & 4 & 1.4 & 1 & 0.966 \\
& 8 & 683 & 6 & 4.7 & 2 & 0.984 \\
& 30 & 467 & 5 & 2.9 & 3 & 0.942 \\
\hline $\mathbf{0 . 9}$ & 1 & 645 & 5 & 1.2 & 1 & 0.941 \\
& 8 & 694 & 8 & 2.4 & 2 & 0.971 \\
& 30 & 733 & 6 & 3.7 & 2 & 0.979 \\
\hline $\mathbf{1 . 5}$ & 1 & 674 & 4 & 1.1 & 1 & 0.937 \\
& 8 & 725 & 7 & 2.8 & 2 & 0.961 \\
& 30 & 778 & 5 & 3.2 & 1 & 0.985 \\
\hline $\mathbf{1 . 6}$ & 1 & 653 & 4 & 1.0 & 1 & 0.924 \\
& 8 & 707 & 5 & 2.1 & 1 & 0.963 \\
& 30 & 760 & 4 & 2.9 & 1 & 0.981 \\
\hline $\mathbf{6 . 0}$ & 1 & 639 & 4 & 0.6 & 1 & 0.892 \\
& 8 & 696 & 3 & 0.9 & 1 & 0.951 \\
& 30 & 766 & 5 & 1.5 & 1 & 0.959 \\
\hline
\end{tabular}


Table 3: Component values of the equivalent circuit in Fig. 9a determined at different processing times (1, 8 and $30 \mathrm{~min})$ in various RCQ conditions $(0.5,0.9,1.5,1.6$ and 6.0).

\begin{tabular}{cccccccc}
\hline RCQ & Proc. Time $(\min )$ & $\mathbf{R}_{\text {el }}(\Omega)$ & $\Delta \mathbf{R}_{\text {el }}(\Omega)$ & $R_{\text {ox }}(\Omega)$ & $\Delta R_{\text {ox }}(\Omega)$ & $\mathbf{C}_{\text {ox }}\left(\times 10^{-6} \mathrm{~F}\right)$ & $\Delta \mathbf{c}_{\text {ox }}\left(\times 10^{-6} \mathbf{F}\right)$ \\
\hline $\mathbf{0 . 5}$ & 1 & 4 & 1 & 28.8 & 1.5 & 4.8 & 0.1 \\
& 8 & 4 & 1 & 30.2 & 1.5 & 15.6 & 1.5 \\
& 30 & 4 & 1 & 19.4 & 1.2 & 14.8 & 1.8 \\
\hline $\mathbf{0 . 9}$ & 1 & 4 & 1 & 28.3 & 1.4 & 4.1 & 0.4 \\
& 8 & 4 & 1 & 30.7 & 1.6 & 7.9 & 0.8 \\
& 30 & 4 & 1 & 32.7 & 1.6 & 11.4 & 1.1 \\
\hline $\mathbf{1 . 5}$ & 1 & 4 & 1 & 29.7 & 1.4 & 3.6 & 0.3 \\
& 8 & 4 & 1 & 32.3 & 1.5 & 8.6 & 0.8 \\
& 30 & 4 & 1 & 34.9 & 1.6 & 9.2 & 0.8 \\
\hline $\mathbf{1 . 6}$ & 1 & 4 & 1 & 28.7 & 1.4 & 3.5 & 0.3 \\
& 8 & 4 & 1 & 31.4 & 1.5 & 6.7 & 0.6 \\
& 30 & 4 & 1 & 34.0 & 1.6 & 8.6 & 0.8 \\
\hline $\mathbf{6 . 0}$ & 1 & 4 & 1 & 27.9 & 1.4 & 2.2 & 0.2 \\
& 8 & 4 & 1 & 30.8 & 1.4 & 3.1 & 0.3 \\
& 30 & 4 & 1 & 34.3 & 1.6 & 4.4 & 0.4 \\
\hline
\end{tabular}




\section{List of figures}

Fig. 1: Evolution of the anodic and cathodic voltage amplitudes with the processing time for different values of the charge quantity ratio RCQ.

Fig. 2: Evolution of the light emission (blue lines) with the corresponding current (black lines) and voltage (red lines) signals recorded over $10 \mathrm{~ms}$ for different values of the charge quantity ratio RCQ and at various processing time.

Fig. 3: Evolution of the delay of light emission with the processing time for various values of the charge quantity ratio RCQ.

Fig. 4: SEM micrographs of the topmost surfaces and cross-sections of the PEO oxide layers elaborated for 30 min under different values of the charge quantity ratio RCQ.

Fig. 5 : Variations of the average total thickness of the PEO oxide layer and of the average thickness of the inner layer with fines porosities as a function of the charge quantity ratio $R C Q$. Measurements are performed at the centre of the processed samples.

Fig. 6 : Schematic description (over 1 current pulse period) of the mechanism of charge accumulation which takes place at the oxide / electrolyte interface during the PEO process of aluminum for three extreme ratios of charge quantity: $R C Q<<0.9, \mathrm{RCQ}=0.9$ and $R C Q \gg>$ 0.9 .

Fig. 7 : Example of the curve fitting for the transient anodic voltage-time response (RCQ = $1.5, \mathrm{t}=30 \mathrm{~min}$ ) using the exponential decay function defined in Eq. (1).

Fig. 8: Evolution of the time constant $\tau$ with the processing time for various values of the charge quantity ratio RCQ. (Time constant is deduced from the fitted anodic voltage-time reponse using Eq. (1)). 
Fig 9: a) Equivalent circuit proposed as a physical interpretation of the transient anodic voltage-time response of the PEO electrolyser system during pulsed bipolar PEO of aluminium. Evolution of the circuits parameters with the processing time for various values of the ratio of charge quantity RCQ: b) Resistance of the PEO oxide layer $\mathrm{R}_{\mathrm{ox}}$ (deduced from Eq. (4)) and c) Capacitance of the PEO oxide layer $\mathrm{C}_{\mathrm{ox}}$ (deduced from Eq. (5)).

Fig. 10: Correlation between the delay in the micro-discharges appearance (delay between the rising edge of the anodic current and the light emission) and the time constant of the electrolyser system during the anodic polarization of a pulsed bipolar PEO of aluminium. 
Figures

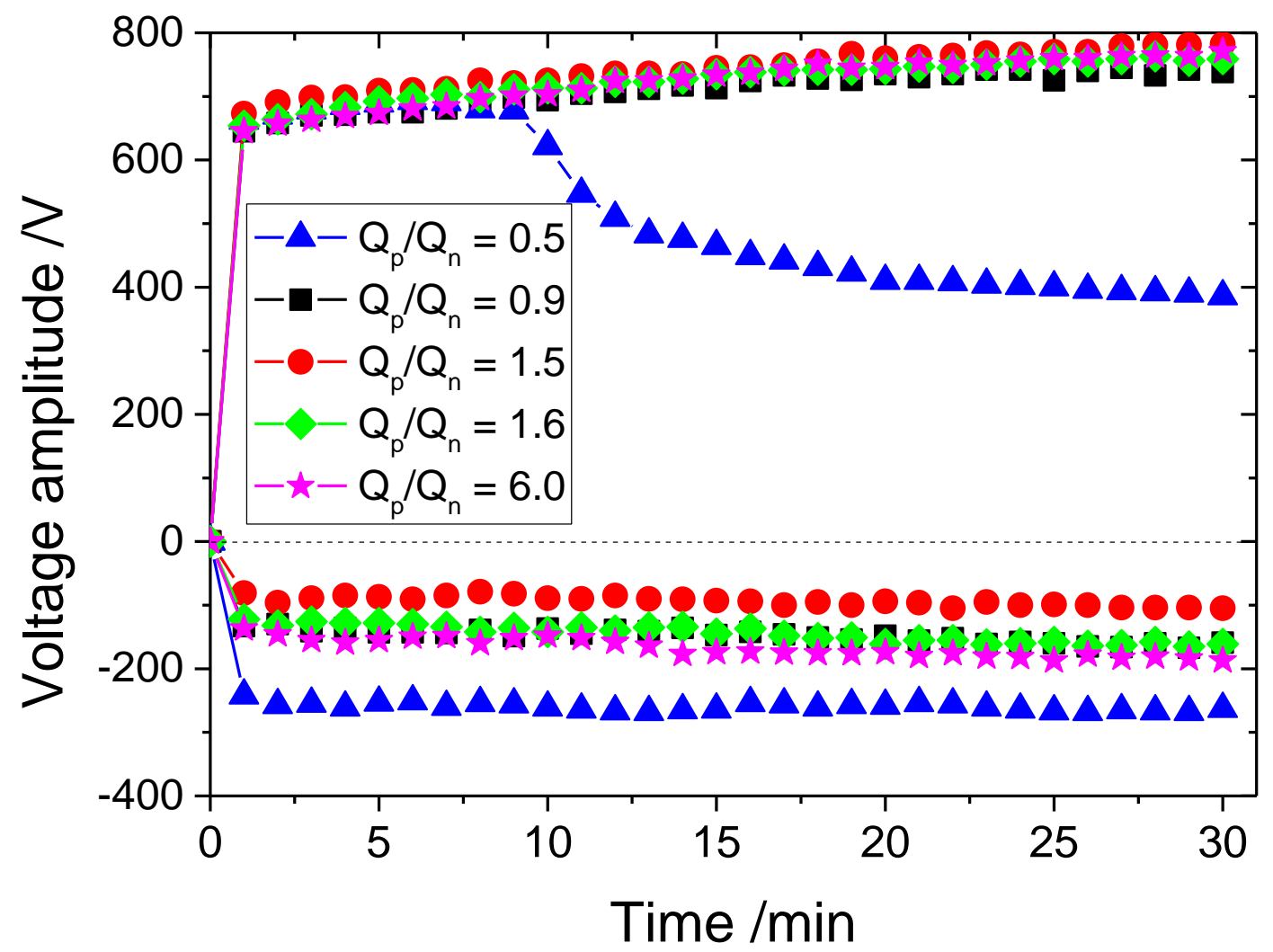

Fig. 1 


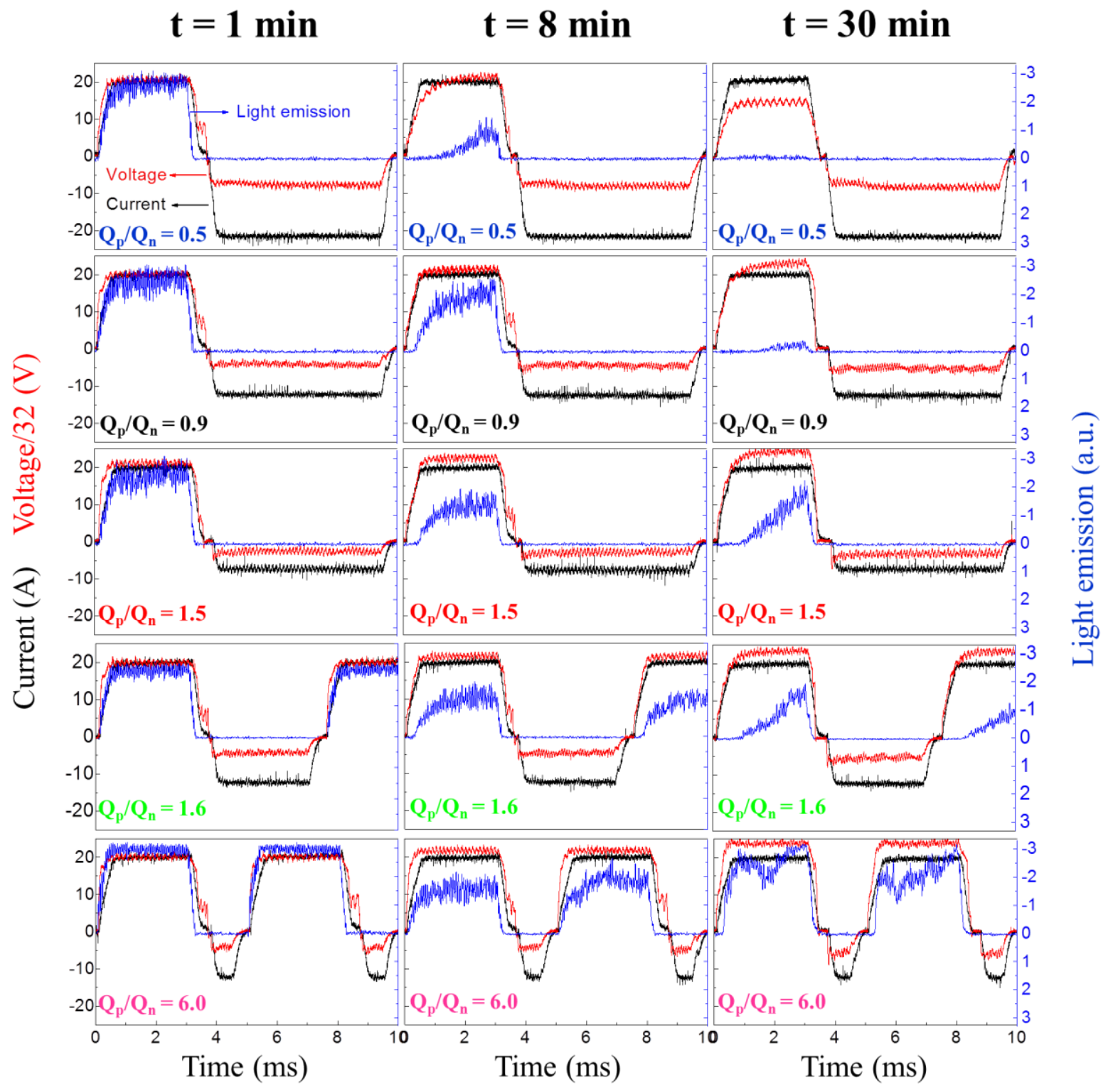

Fig. 2 


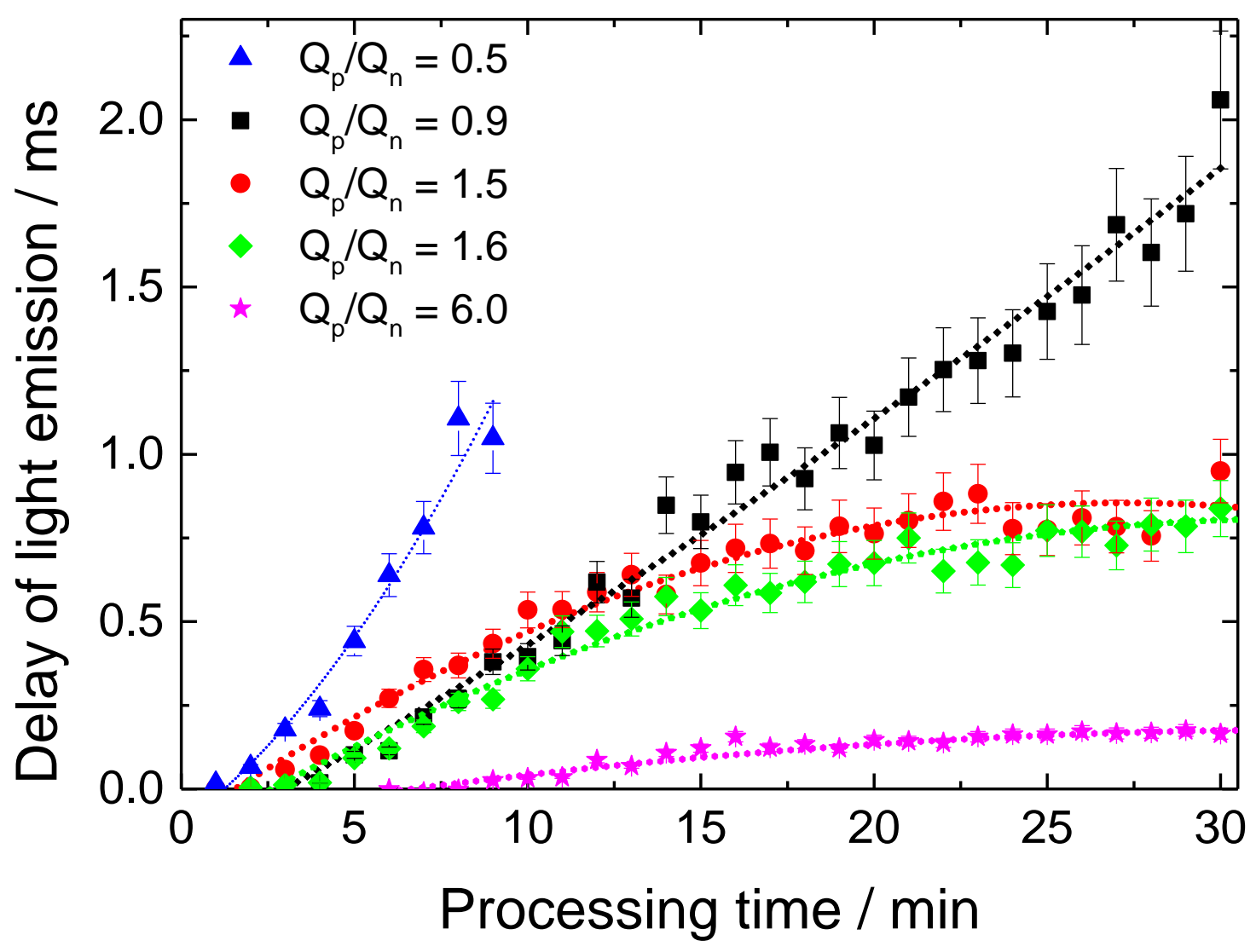

Fig. 3 
Top-surface
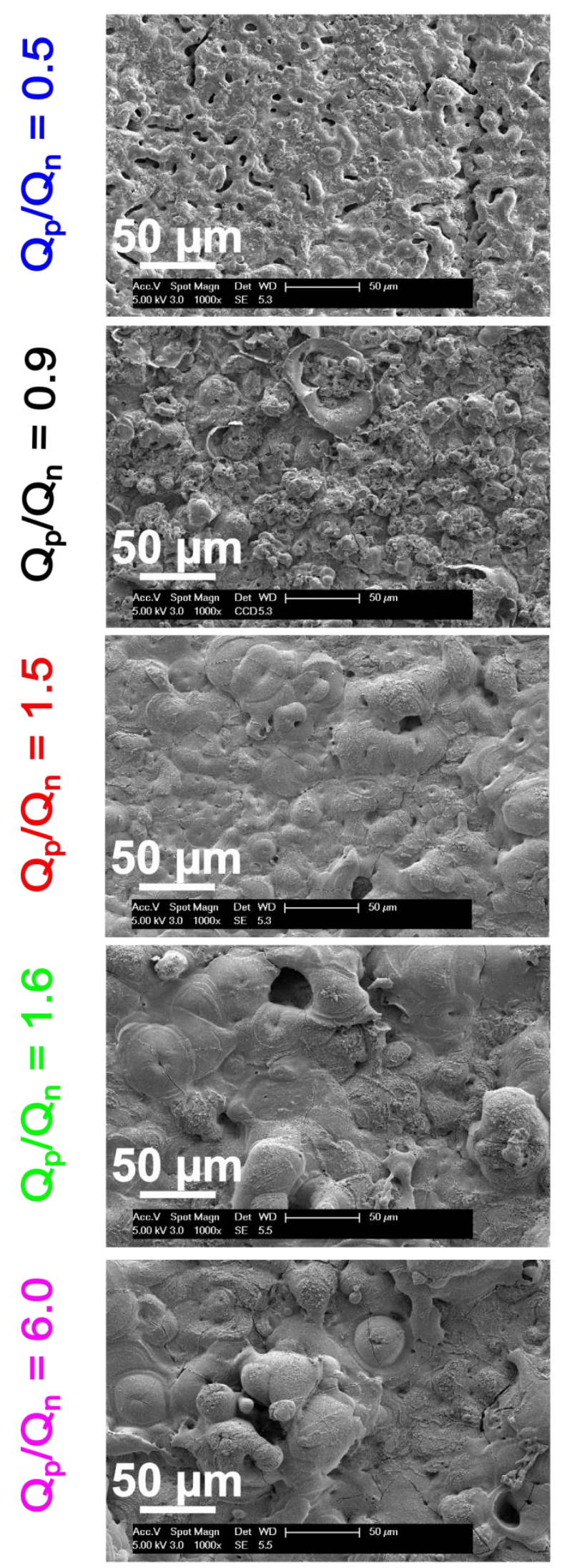

\section{Cross-section}
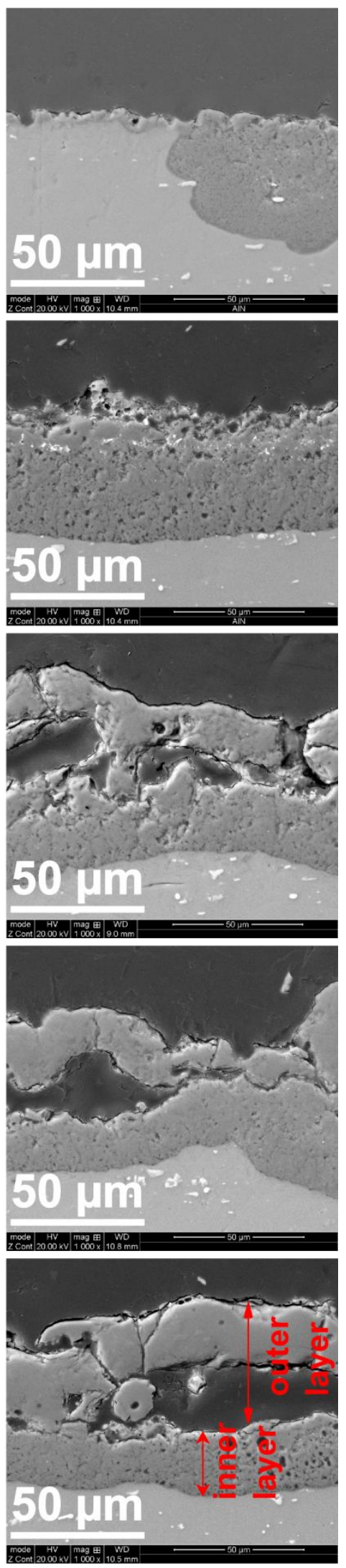

Fig. 4 


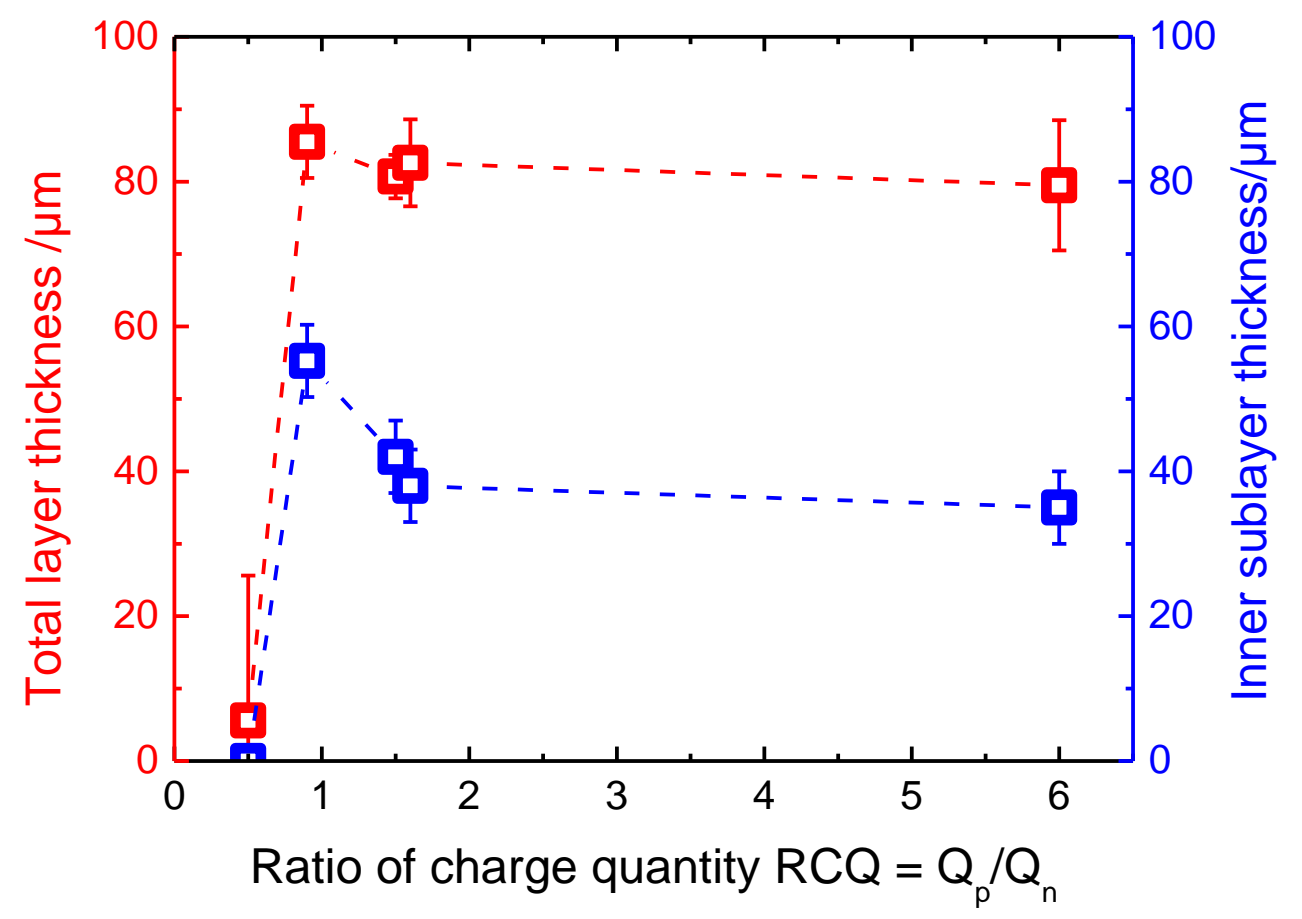

Fig. 5 


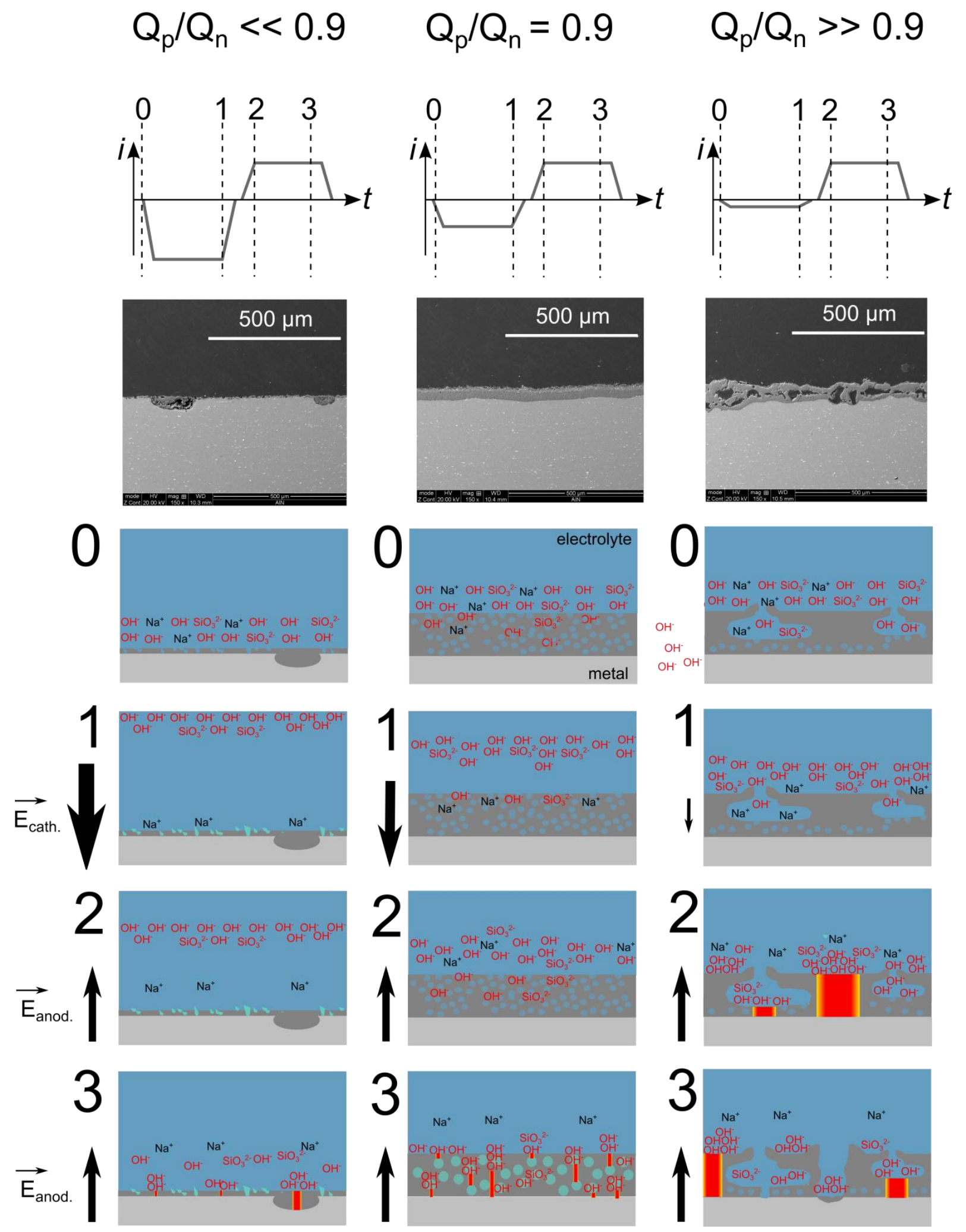

Fig. 6 


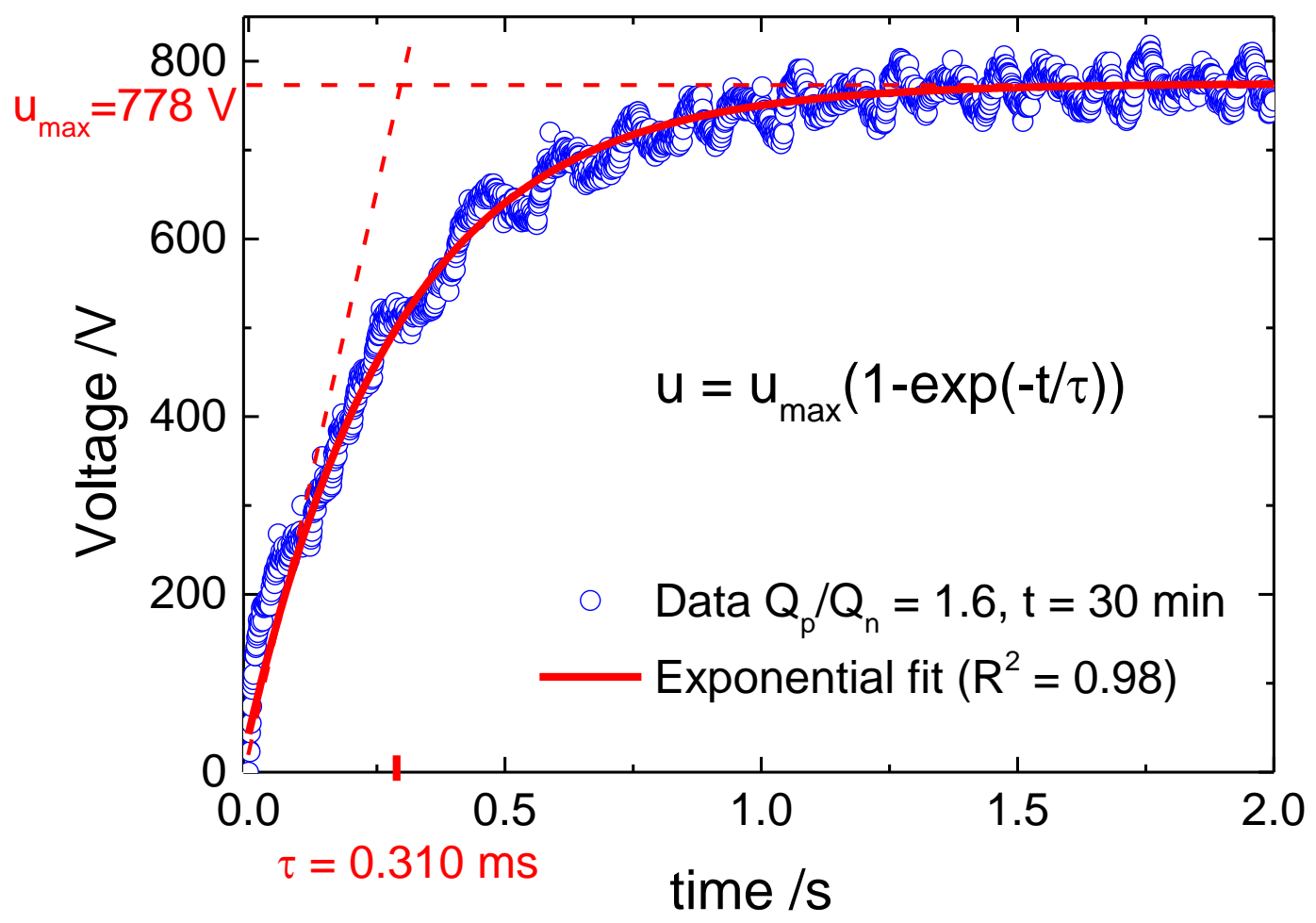

Fig. 7 : 


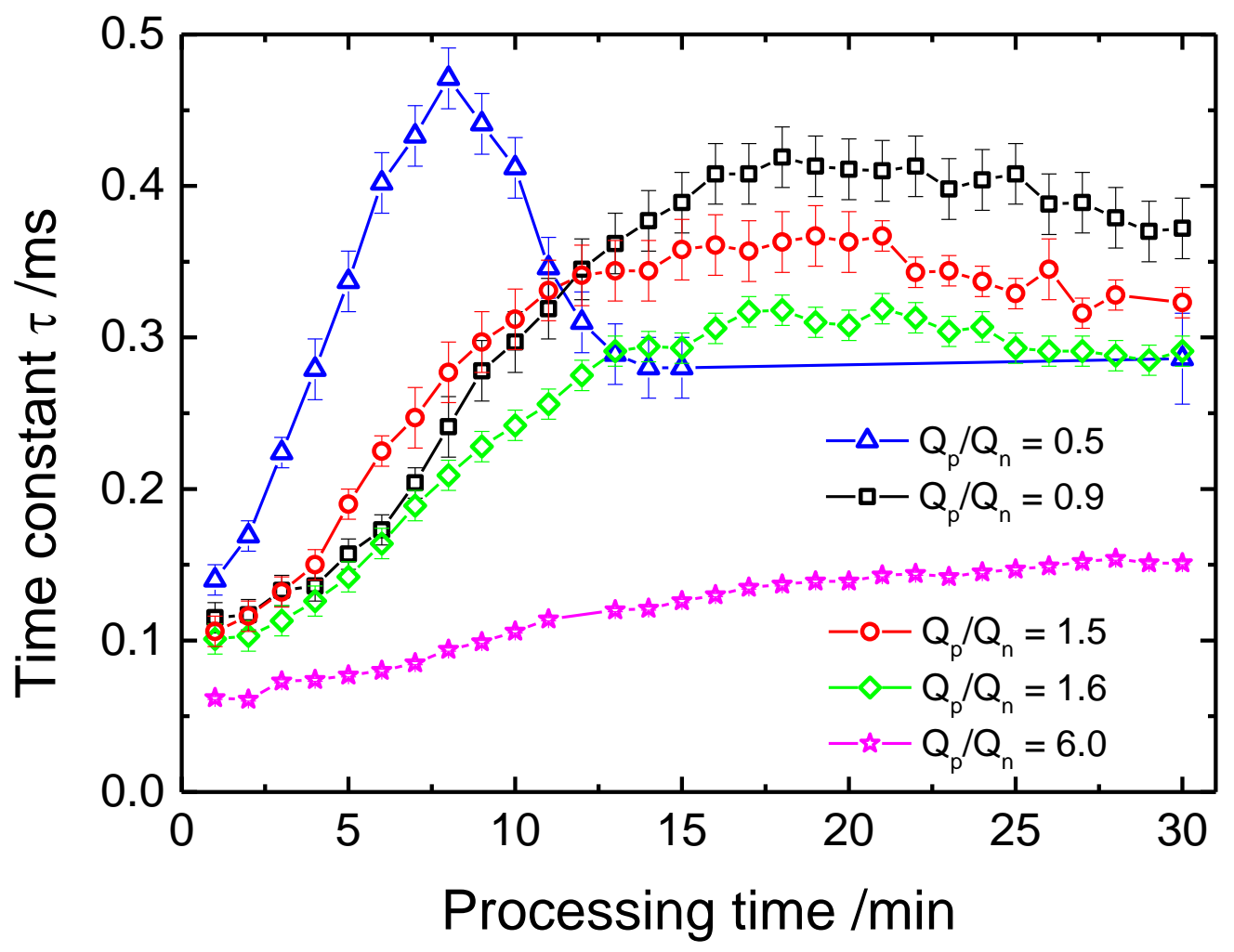

Fig. 8 


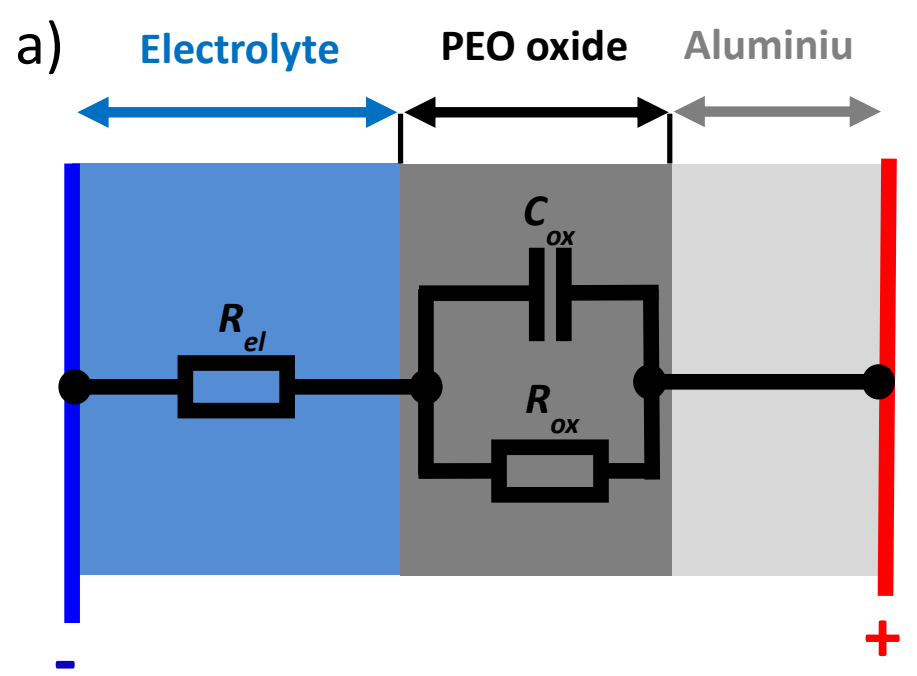

b)
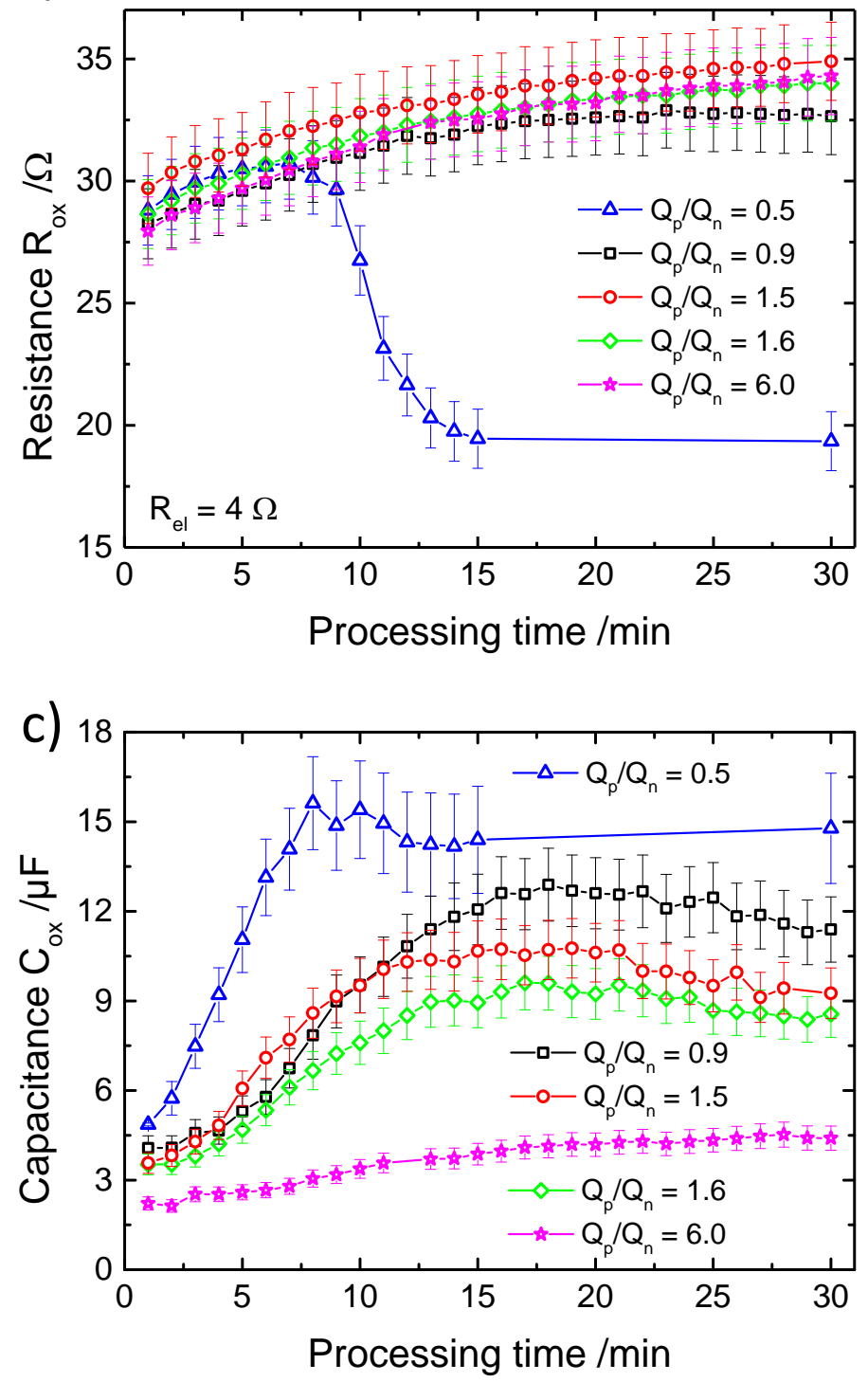

Fig. 9 


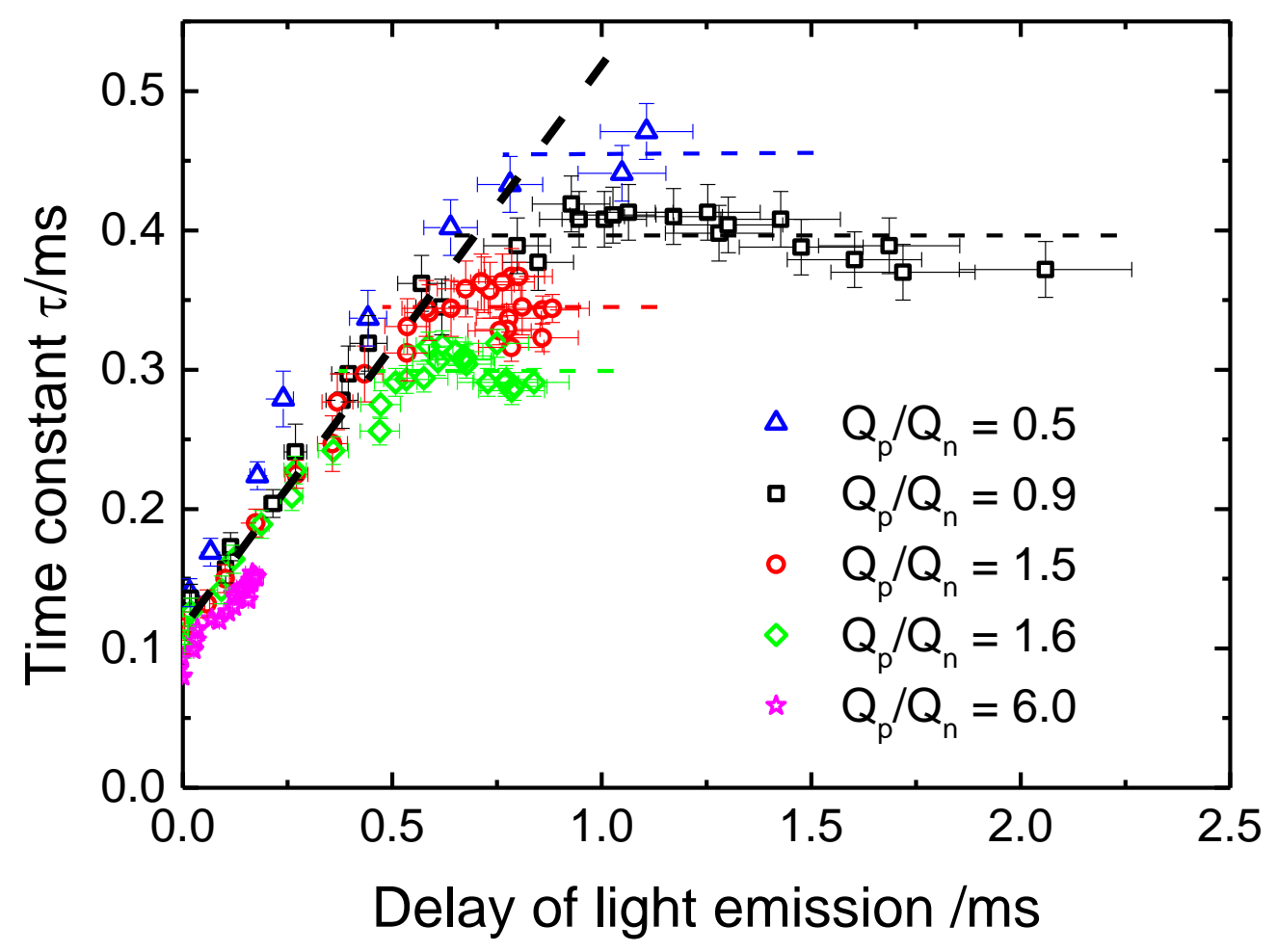

Fig. 10 


\section{Supplementary data}

Fig. S1: Schematic representation of the pulsed bipolar current waveforms designed to investigate the influence of the cathodic half-period of the current on the PEO process. a) Ratio of charge quantity $\mathrm{RCQ}=\mathrm{Q}_{\mathrm{p}} / \mathrm{Q}_{\mathrm{n}}=0.5 ; 0.9$ and 1.5 by changing the cathodic current amplitude $\mathrm{I}_{\text {cath. }}$ b) Ratio of charge quantity $\mathrm{RCQ}=\mathrm{Q}_{\mathrm{p}} / \mathrm{Q}_{\mathrm{n}}=0.9 ; 1.6$ and 6.0 by changing the cathodic current pulse duration $t_{\text {cath. }}$

Fig. S2: Spatial distribution of the micro-discharges over the processed surface for different values of the charge quantity ratio RCQ and at various processing time. Each picture corresponds to the integration of 475 successive images spanning over the anodic current halfperiod $(3.8 \mathrm{~ms})$. Coloured scale bar indicates the number of micro-discharges events that were detected.

Fig. S3: a) Evolution with the processing time for different values of the charge quantity ratio RCQ of a) the surface density of the micro-discharges. b) The average size of the microdischarges with the processing time for different values of the charge quantity ratio RCQ. c) The average lifetime of the micro-discharges.

Fig. S4 : a) XRD patterns (using Bragg-Brentano geometry) of the PEO oxide layers grown for 30 min with different rvalues of the charge quantity ratio RCQ. (Performed at the centre of the processed samples). b) Selected region of the XRD patterns where (113) $\alpha-\mathrm{Al}_{2} \mathrm{O}_{3}$ and (400) $\eta-\mathrm{Al}_{2} \mathrm{O}_{3}$ peaks are found. c) Variation of the $\alpha-\mathrm{Al}_{2} \mathrm{O}_{3}$ content in the PEO layer (calculated from XRD measurements) as a function of the charge quantity ratio $R C Q$. 
a)

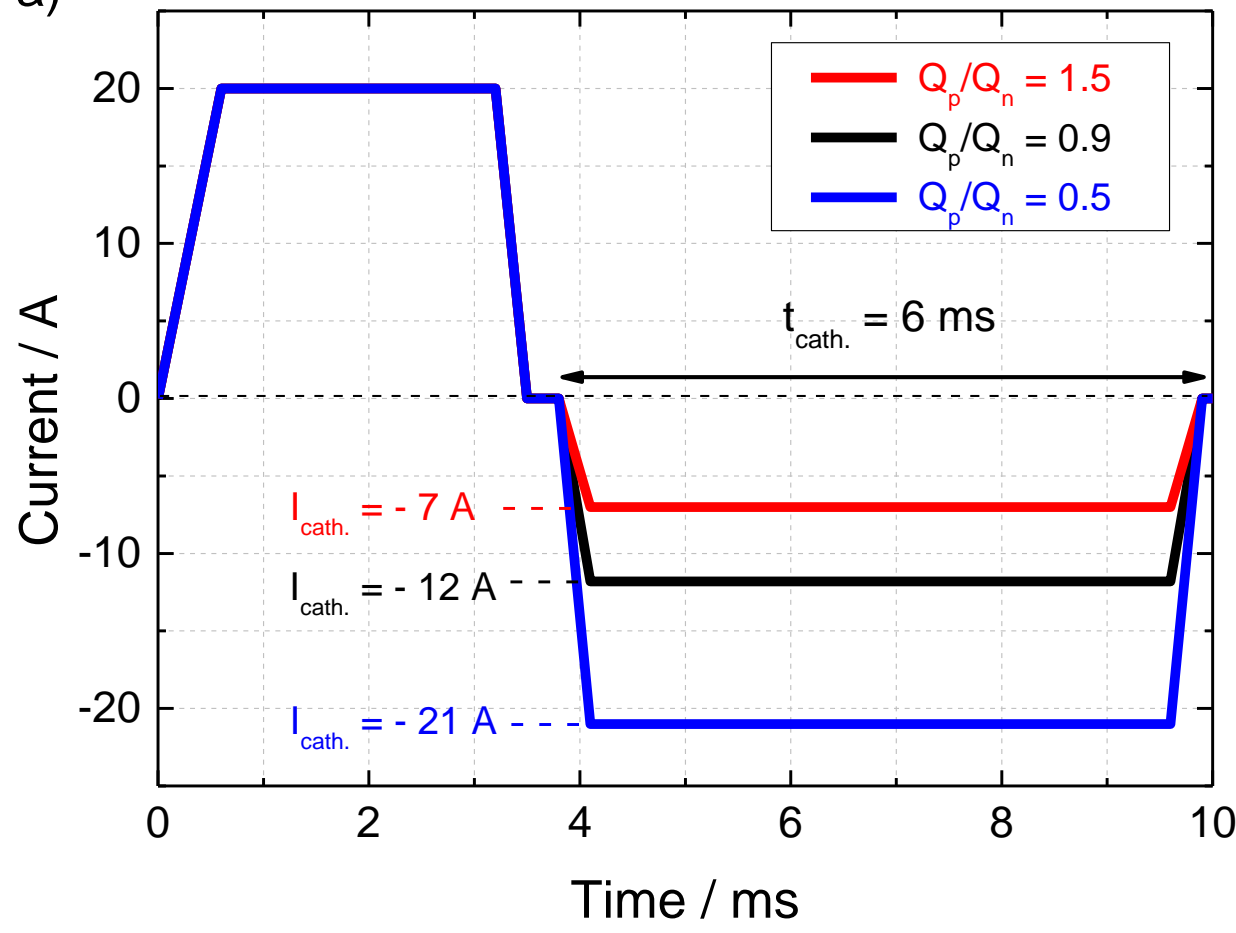

b)

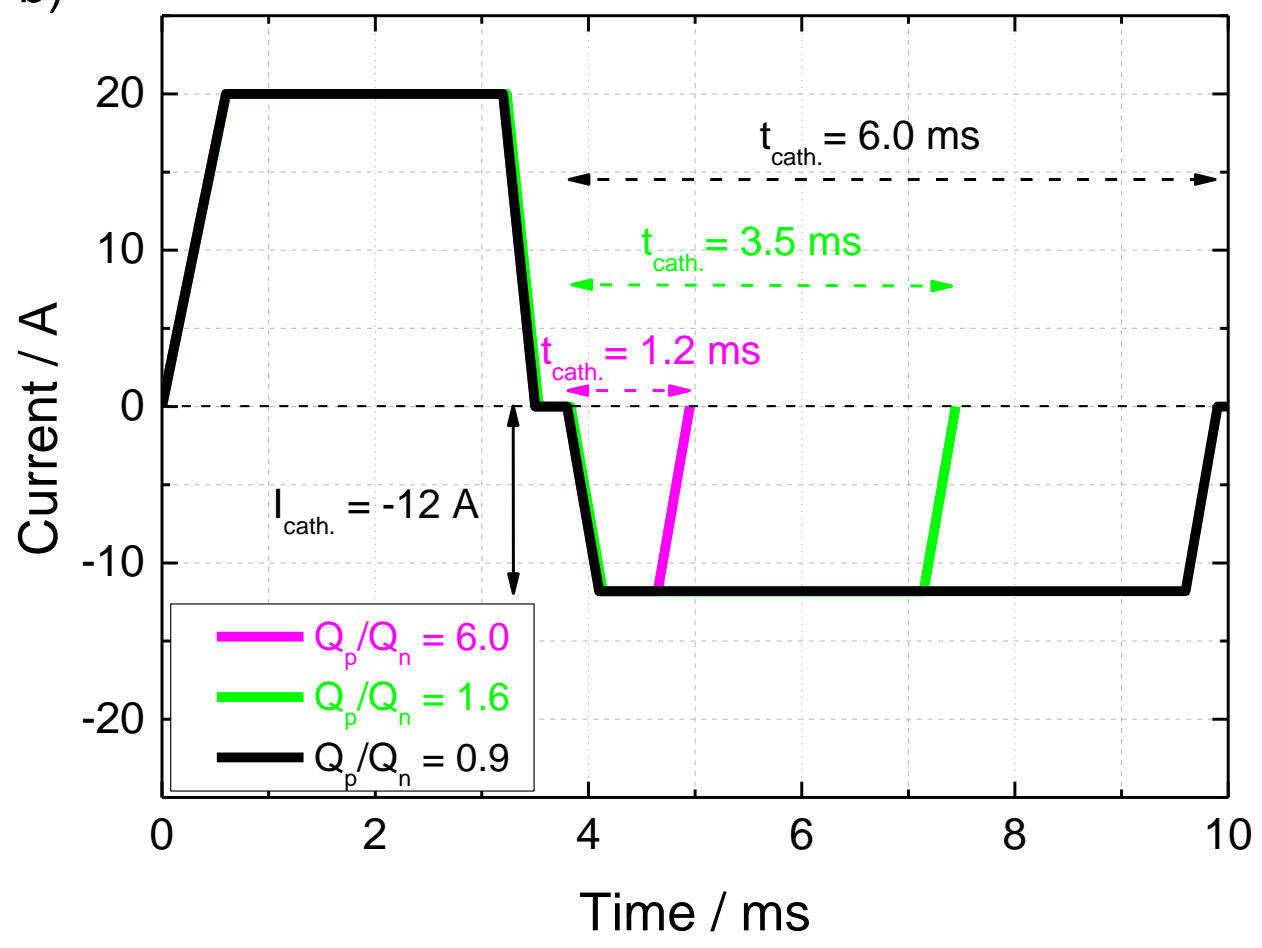

Fig. S1 


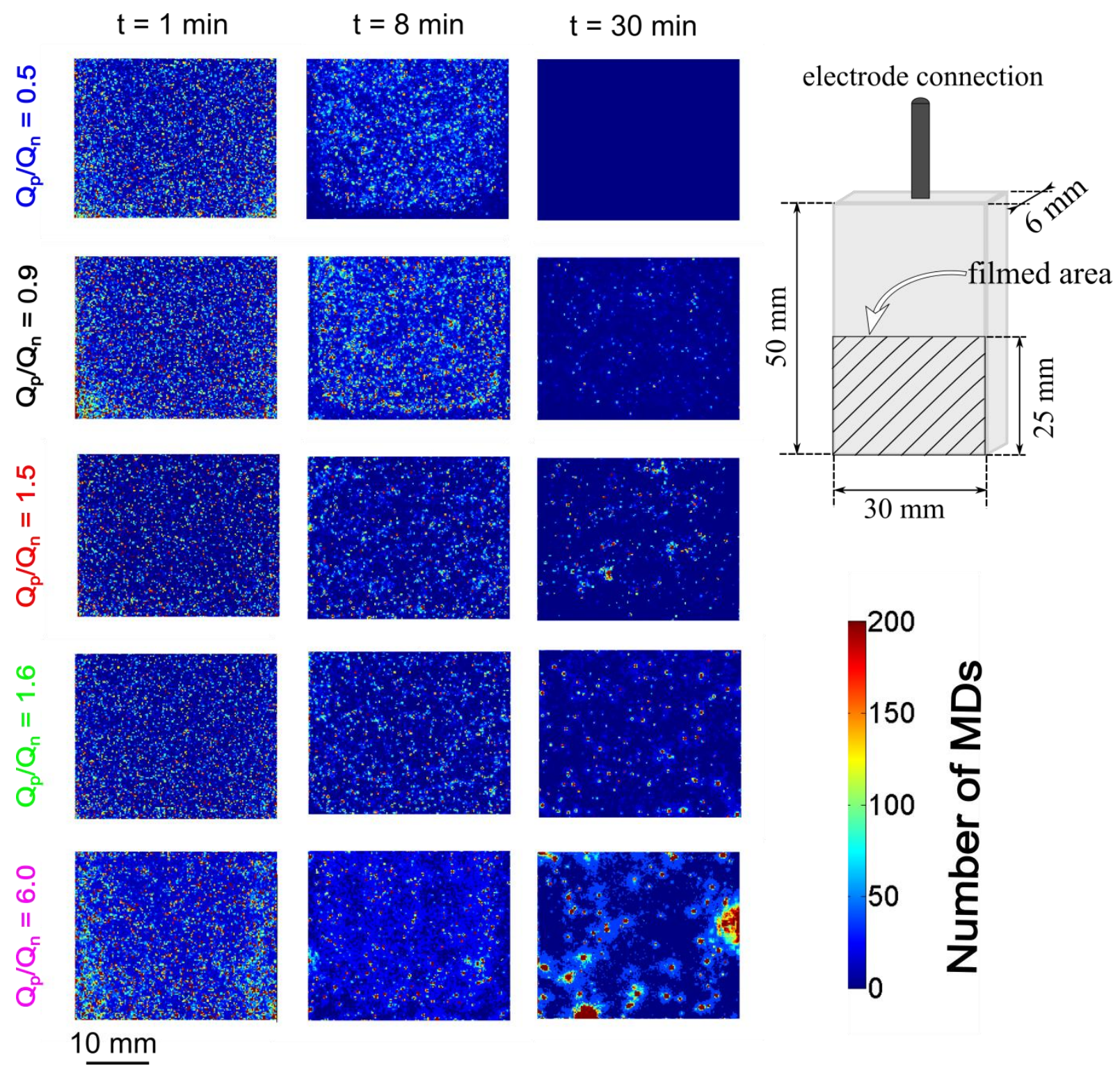

Fig. S2 

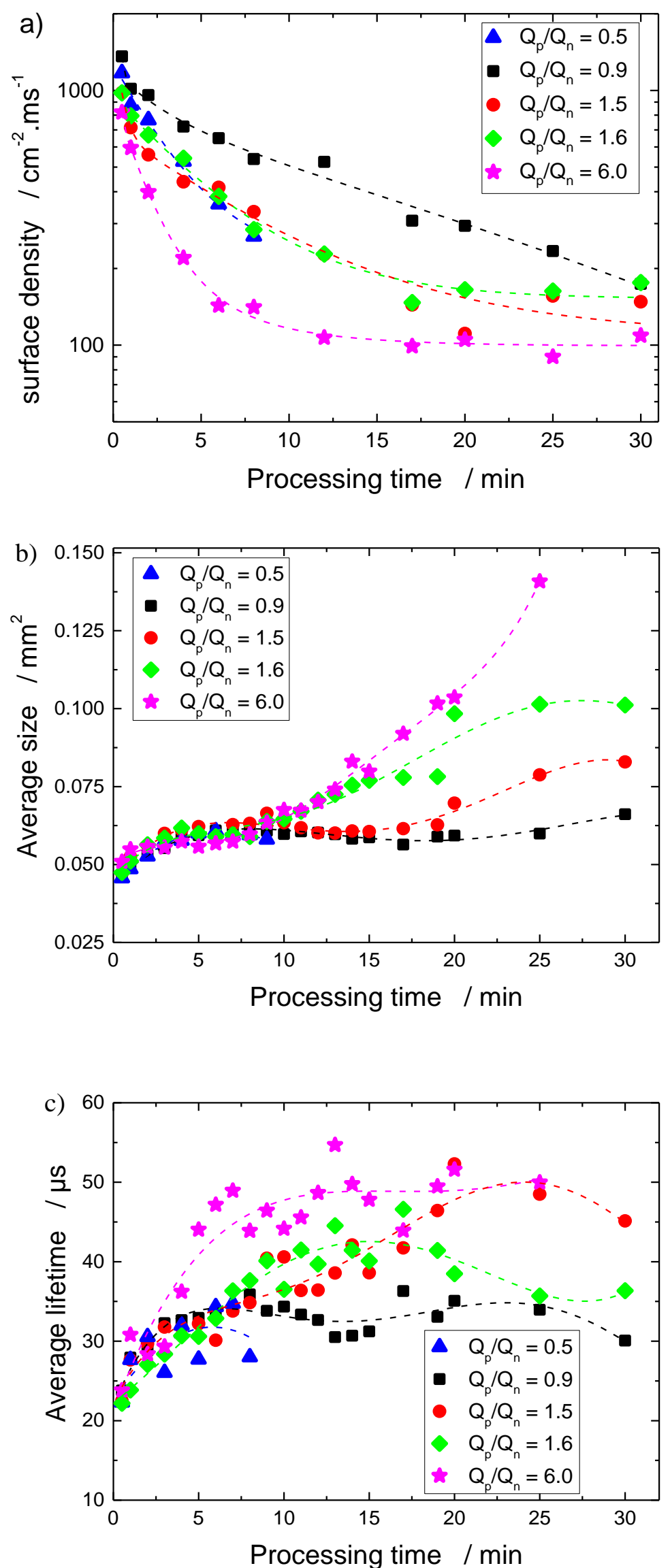

Fig. S3 


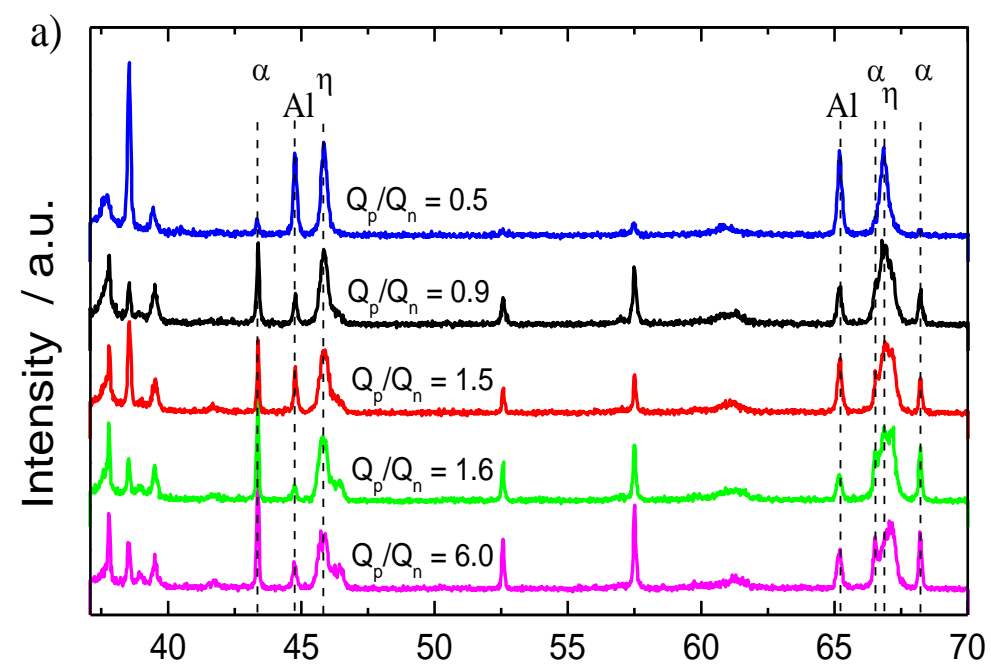

$2 \theta / \circ$
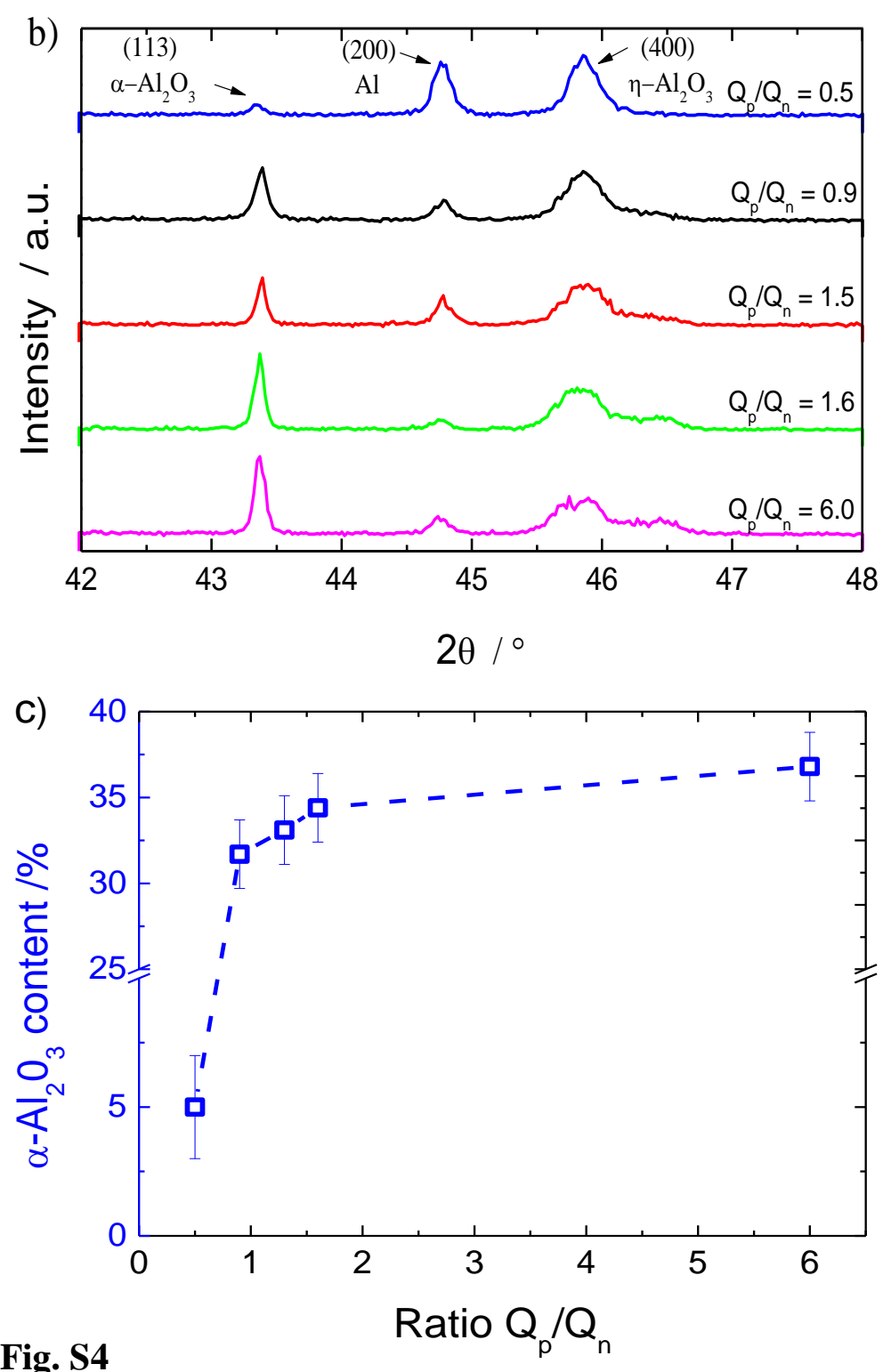